\title{
Rhodnius, Golden Oil, and Met: A History of Juvenile Hormone Research
}

\author{
Lynn M. Riddiford*
}

Department of Biology, Friday Harbor Laboratories, University of Washington, Friday Harbor, WA, United States

Juvenile hormone $(\mathrm{JH})$ is a unique sesquiterpenoid hormone which regulates both insect metamorphosis and insect reproduction. It also may be utilized by some insects to mediate polyphenisms and other life history events that are environmentally regulated. This article details the history of the research on this versatile hormone that began with studies by V. B. Wigglesworth on the "kissing bug" Rhodnius prolixus in 1934, through the discovery of a natural source of $\mathrm{JH}$ in the abdomen of male Hyalophora cecropia moths by C. M. Williams that allowed its isolation ("golden oil") and identification, to the recent research on its receptor, termed Methoprene-tolerant (Met). Our present knowledge of cellular actions of $\mathrm{JH}$ in metamorphosis springs primarily from studies on Rhodnius and the tobacco hornworm Manduca sexta, with recent studies on the flour beetle Tribolium castaneum, the silkworm Bombyx mori, and the fruit fly Drosophila melanogaster contributing to the molecular understanding of these actions. Many questions still need to be resolved including the molecular basis of competence to metamorphose, differential tissue responses to $\mathrm{JH}$, and the interaction of nutrition and other environmental signals regulating $\mathrm{JH}$ synthesis and degradation.

Institut de Biología Evolutiva (IBE),

Spain

Thomas Roeder,

University of Kiel, Germany

*Correspondence:

Lynn M. Riddiford

Imr@uw.edu

Specialty section:

This article was submitted to

Epigenomics and Epigenetics,

a section of the journal

Frontiers in Cell and Developmental

Biology

Received: 25 May 2020

Accepted: 06 July 2020

Published: 07 August 2020

Citation:

Riddiford LM (2020) Rhodnius, Golden Oil, and Met: A History

of Juvenile Hormone Research.

Front. Cell Dev. Biol. 8:679.

doi: 10.3389/fcell.2020.00679

\section{INTRODUCTION}

Serendipity is often the key to novel and fundamental discoveries. Physiologists early on are taught the August Krogh Principle: "For a large number of problems there will be some animal of choice or a few such animals on which it can be most conveniently studied" (Krogh, 1929). The history of juvenile hormone $(\mathrm{JH})$ research is filled with examples of this as will be clear in the following account.

Experimental endocrinology began with Berthold who in 1849 transplanted testes into castrated roosters and showed that they caused the return of the normal secondary sex characteristics (enlarged combs and wattles) (Soma, 2006). In 1856, Brown-Séquard showed that the adrenal gland was essential to life (Aminoff, 2017), then later showed that mammalian testicular extracts influence secondary sex characteristics in other animals and purportedly aging in men as well (Brown-Séquard, 1889). The first work on hormonal control of metamorphosis was that of Gudernatsch (1912) who found that extracts of mammalian thyroid were sufficient to cause precocious metamorphosis of frog tadpoles, indicating a universality of function of these extracts. All these findings showed that endocrine organ extracts contained substances that when injected into the blood could act on particular target organ(s); these substances were named "hormones" (Starling, 1905). 
Stefan Kopeć working in Cracow, Poland between 1908 and 1912 was the first to show that in insects, unlike in birds and mammals, the secondary sex characteristics were not dependent on gonadal hormones (Cymborowski, 1981). He went on to demonstrate in the gypsy moth, Lymantria dispar, that the brain secreted a hormone that was necessary for metamorphosis (Kopeć, 1917, 1922). This "brain hormone" was the first known neurosecretory hormone in insects and was later called "prothoracicotropic hormone" (PTTH) when the particular pair of cells was isolated and shown to stimulate ecdysone secretion by the prothoracic glands of the tobacco hornworm, Manduca sexta, in vitro (Agui et al., 1979).

\section{WIGGLESWORTH AND Rhodnius}

In 1934, working with the bloodsucking, kissing bug, Rhodnius prolixus (the vector of Chagas disease), Vincent B. Wigglesworth was the first to show that there was a hormone that circulated in the nymphal hemolymph that prevented metamorphosis. Rhodnius was ideal for these experiments since they only molted after a blood meal and they could be parabiosed (i.e., two could be attached together by the anterior ends so that they shared circulating hemolymph). Normally a nymph would molt 6 days after feeding, but when decapitated immediately after feeding, it never molted (Wigglesworth, 1934; Figure 1). If, however, decapitation was delayed until 3 days after feeding, the molt proceeded normally. Through a series of parabiosis experiments, Wigglesworth (1934) then showed that there was a hormone released from the head after feeding that initiated the molting process. Moreover, parabiosis experiments with penultimate fourth and final fifth instar nymphs showed that there was also a hormone released from the head region that inhibited metamorphosis (Figure 2). Parabiosis of a fed headless fourth instar to a headless metamorphosing nymph caused precocious metamorphosis of the fourth instar nymph. In contrast, a fed headless fifth instar nymph parabiosed to a molting fourth instar nymph formed a supernumerary nymph. Histological studies showed that the head contained a brain and the posterior sympathetic ganglion that innervated a single median gland, the corpus allatum, located at the back of the head above the subesophageal ganglion in a hemolymph-filled sinus (Figure 2). Moreover, the corpus allatum showed cyclical changes during larval molting and metamorphosis. Based on these studies, Wigglesworth (1934) concluded that both the "molting" and "inhibitory" hormones come from the corpus allatum.

From further parabiosis and corpus allatum implantation experiments, Wigglesworth (1936) concluded that the corpus allatum was the source of the inhibitory hormone for metamorphosis. In 1940, he further showed by implantations of various organs into fed decapitated fourth instar nymphs that only the corpus allatum secreted the "inhibitory hormone" and the brain (the dorsal half) the "molting hormone" (Wigglesworth, 1940). At this point, he named the metamorphosis-inhibitory hormone "juvenile hormone." $\mathrm{He}$ also compared the abdominal epidermal changes during a nymphal molt and at metamorphosis. Based on this comparison, Wigglesworth

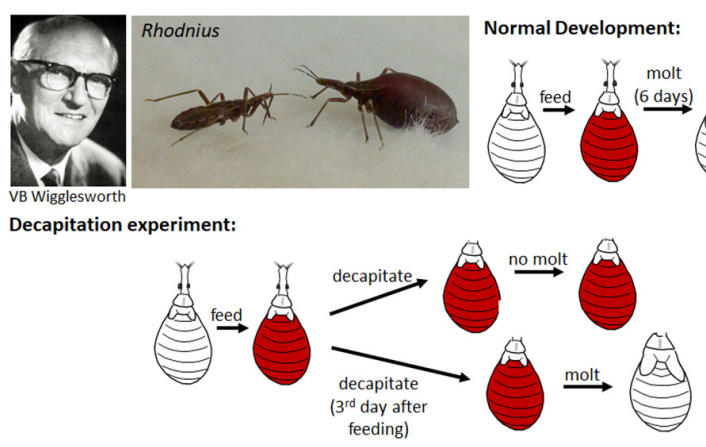

FIGURE 1 | Top: Vincent B. Wigglesworth (left); non-fed (left) and blood-fed (right) nymphs of Rhodnius prolixus (center); cartoon of the normal development of a nymph which after feeding on a blood meal (orange) molts to the next nymphal instar 6 days later. Bottom: Cartoon of decapitation experiments shows that decapitation immediately after feeding prevents the molting but decapitation 3 days after feeding does not. Photos of Wigglesworth from Phillips (2004) and of Rhodnius taken by Timothy Bradley and Catherine Loudon from Knight (2014) (reproduced with permission).

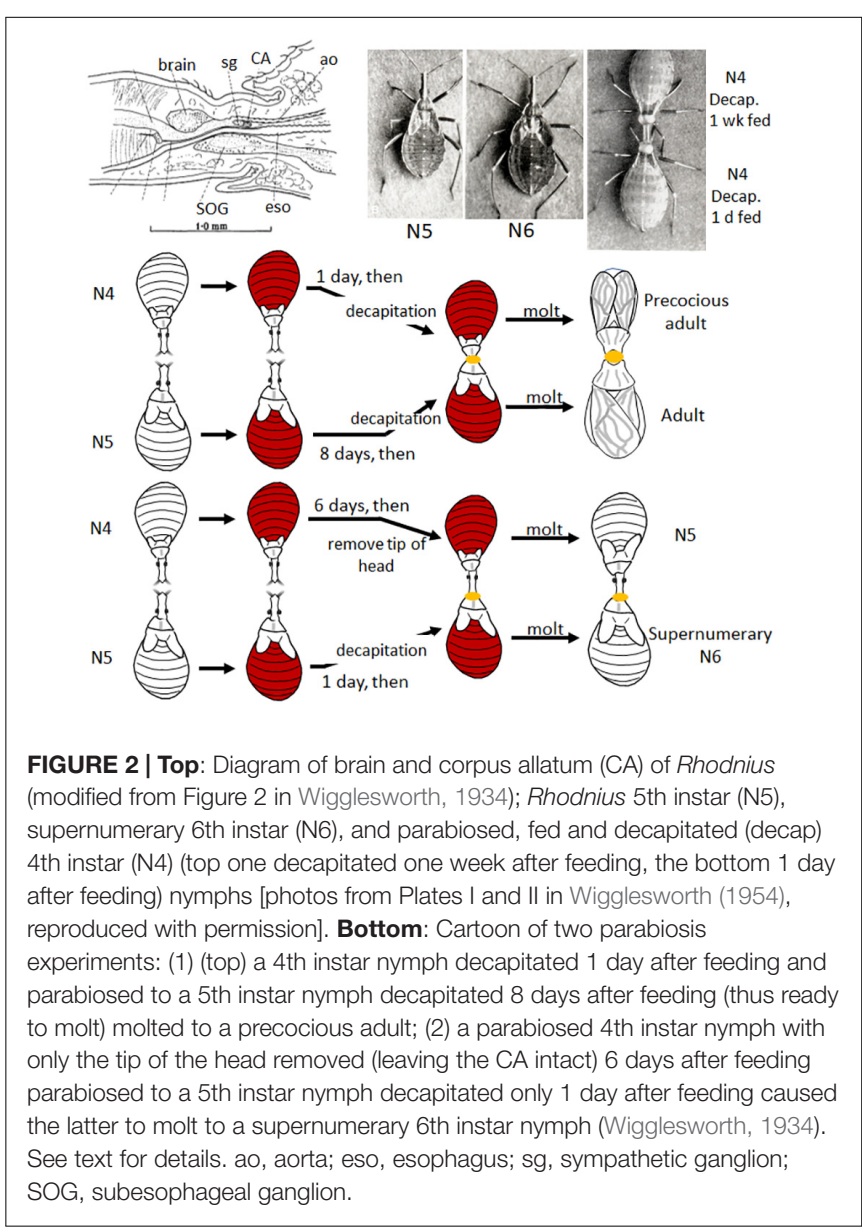

hypothesized that metamorphosis at the cellular level occurs only when the molting hormone is present and activates the "imaginal system" (Wigglesworth, 1940). If, however, JH is also present, it activates the nymphal system and prevents the production of 
adult structures. Later guided by the findings of Williams (1947, 1948) on the wild silkmoth, Hyalophora (formerly Platysamia) cecropia (commonly called Cecropia) (see below), Wigglesworth (1952) showed that the thoracic glands of Rhodnius secreted the molting hormone after activation by a hormone from the brain.

Wigglesworth also showed that the corpus allatum reactivated in the adult and regulated ovarian maturation in the female and accessory gland development in the male (Wigglesworth, 1936). The corpora allata were first described in the goat moth caterpillar, Cossus cossus, as "petits ganglions de la tete" (Lyonet, 1762). Later Nabert (1912) described their structure for many different insects, but their function(s) was unknown. Holmgren in 1909 and Ito in 1918 had noted changes in size of the corpora allata associated with reproductive maturation in termites and Lepidoptera, respectively (as cited in Wigglesworth, 1985), but no one had experimentally tackled the problem. Thus, Wigglesworth was the first to demonstrate that a hormone regulated reproduction in insects; and, moreover, that hormone was $\mathrm{JH}$, the same hormone that regulated metamorphosis.

His findings spawned a whole series of experiments in many different insects on the role of the corpora allata in reproduction. In most insects, the corpora allata were found necessary for ovarian maturation - the grasshopper, Melanoplus differentialis (Pfeiffer, 1939), various flies (Thomsen, 1940; Vogt, 1942), and the cockroach, Leucophaea maderae (Scharrer, 1946). However, in a few insects such as the walking stick, Carausius (formerly Dixippus) morosus (Pflugfelder, 1937) and the silkmoth, Bombyx mori (Bounhiol, 1939), egg development occurred normally after allatectomy. These early studies were also notable for the number of women working in this area-Isabella Pfeiffer, Ellen Thomsen, Marguerite Vogt, and Berta Scharrer. Studies since then show that $\mathrm{JH}$ plays nearly a universal role in the regulation of insect reproduction although the details of the precise role it plays depends on the insect's life history (see reviews by Wigglesworth, 1985; Wyatt and Davey, 1996; Raikhel et al., 2005; Santos et al., 2019).

\section{CONFIRMATION OF THE CORPORA ALLATA AS THE SOURCE OF JH}

Bounhiol (1938) working with the silkworm, B. mori, showed that removal of the corpora allata (allatectomy) from early instar larvae caused precocious metamorphosis but removal in the final (fifth) instar had no effect on the onset of metamorphosis (Figure 3, top). The allatectomized larva formed a normal cocoon and subsequently a normal pupa and adult. At about the same time, Pflugfelder (1937) and Radtke (1942) showed that loss of the corpora allata caused precocious metamorphosis in Carausius, and the mealworm, Tenebrio molitor, respectively.

At the end of the 1930s, Piepho (1938a) and Kühn and Piepho (1940) used larval integumental (epidermis plus overlying cuticle) implants in Galleria larvae to study hormonal control of molting and metamorphosis. The implants molted with the host and produced the type of cuticle dictated by the hormonal environment. Thus, implants from both last instar larvae (Figure 3, bottom center) and first instar larvae (Figure 3, bottom right) that were placed in a final instar larval host metamorphosed with the host.

Also, in the late 1930s, Helen Tsui-ying Lee at Sun Yat-sen University in Canton, China studied the prothoracic glands of lepidopteran larvae and their innervation and was the first to suggest that these glands were endocrine in nature and worthy of study by insect physiologists (Lee, 1948). However, her study was not published until 1948 due to the Japanese invasion of China in 1938. By the time of the publication of her article, the Japanese scientist Soichi Fukuda had published his classic articles on the commercial silkworm, B. mori, showing the role of the prothoracic glands in pupation (Fukuda, 1940a,b) and of both the corpora allata and prothoracic glands in larval molting (Fukuda, 1944).

\section{WILLIAMS AND Hyalophora cecropia (CECROPIA), A NATURAL SOURCE OF JH}

Carroll M. Williams grew up in Richmond, VA and loved to play around the James River that ran through the city. There he encountered among the insects he collected, the large saturniid moth, H. cecropia, whose pupal quiescence (diapause) inside its cocoon over the winter intrigued him. When he began his postdoctoral studies as a Junior Fellow in the Department of Biology at Harvard University in 1941, he started to work on this problem. His first studies concerned the role of the brain and prothoracic glands [recently implicated by Wigglesworth (1940) and Bounhiol (1945) to be involved in the metamorphosis of Rhodnius and Bombyx, respectively] in promoting development of the Cecropia pupa into the moth in the spring. In a series of extirpation and implantation experiments, he showed that the brain was responsible for activating the prothoracic glands to cause adult development (Williams, 1946, 1947, 1948, 1952). Moreover, chilling the pupae at $6^{\circ} \mathrm{C}$ for at least 10 weeks was sufficient to allow activation of the brain when the pupae were brought back to room temperature (Williams, 1956a).

\section{Serendipitous Discovery of a Natural Source of JH}

In the experiments described above on the role of the brain in terminating diapause, Williams became intrigued with the technique of parabiosis that Wigglesworth had used. Saturniid moths do not feed as adults so mate, lay their eggs and die within about 10 days. Therefore, Williams hypothesized that parabiosis of an adult to a pupa might allow the moth to live longer. When he parabiosed a headless Cecropia moth to a chilled diapausing pupa and kept the pair at $25^{\circ} \mathrm{C}$, the moth did live longer. To his surprise, however, the pupa developed into a "second pupa" rather than to a normal adult! Although this experiment were done in the early 1950s, it was not published until 1963 (Williams, 1963). In a series of experiments to explore this phenomenon, he discovered that the "second pupa" was only formed when the parabiotic partner was either a Cecropia or a Samia cynthia (Cynthia) male moth (Williams, 1959, 
1963; Figure 4). Cecropia pupae parabiosed to female moths of either species or to Antheraea polyphemus (Polyphemus) moths developed into normal adults. Moreover, the abdomens of the male Cecropia or Cynthia moths were sufficient to cause the formation of the second pupae and therefore were the repository for the "juvenile hormone" from the corpora allata that was responsible for the phenomenon (Williams, 1956b, 1959, 1963).

He found that chilled Polyphemus pupae were the best assay animals for JH activity (Williams, 1959) and proceeded to make ether extracts of Cecropia abdomens to isolate the hormone (Williams, 1956b; Figure 4). This extract was yellow due to the carotenoids in Cecropia fat body so he called it the "golden oil." During his sabbatical year in Wigglesworth's laboratory in Cambridge, he further purified and characterized the "golden oil" (Williams, 1956b). Using this extract, Wigglesworth painted his initials VBW on abraded cuticle of final instar nymphs of Rhodnius and showed that these initials were present as newly synthesized nymphal cuticle surrounded by adult cuticle after metamorphosis (Wigglesworth, 1958), confirming that this hormone could act on various insect orders. The $\mathrm{JH}$ in this "golden oil" was not chemically determined until 1967 when Röller et al. (1967) at the University of Wisconsin identified the active compound as the sesquiterpenoid methyl dl-trans, trans, cis10-epoxy-7-ethyl-3,11-dimethyl-2,6-tridecadienoate (JH I) (for a review of the chemistry, see Röller and Dahm, 1968; Figure 5) and subsequently showed that the same compound was released from male Cecropia corpora allata in vitro (Röller and Dahm, 1970). Meyer et al. (1968) found a second hormone, JH II (methyl dl-trans,trans,cis-10,11-epoxy3, 7, 11-trimethyl-2,6-tridecadienoate) (Figure 5) as a minor component of the "golden oil." Nearly 10 years later Shirk et al. (1976) showed that the JH was stored in the male accessory gland, not in the abdominal fat body (Figure 4). Moreover, the male corpora allata secreted $\mathrm{JH}$ acid that was then converted into $\mathrm{JH}$ by $\mathrm{JH}$ esterase in the accessory gland (Peter et al., 1981).

Juvenile hormones I and II were subsequently shown to be found only in Lepidoptera (Schooley et al., 1984). JH III (Figure 5) was first isolated by culturing adult female corpora allata of another lepidopteran, the tobacco hawk moth, M. sexta (Judy et al., 1973) and subsequently shown to be the JH of most other insects (Schooley et al., 1984). JH 0 and 4-methylJH I (Figure 5) were found in Manduca embryos (Bergot et al., 1980). JHs with modifications of the epoxide moiety are found

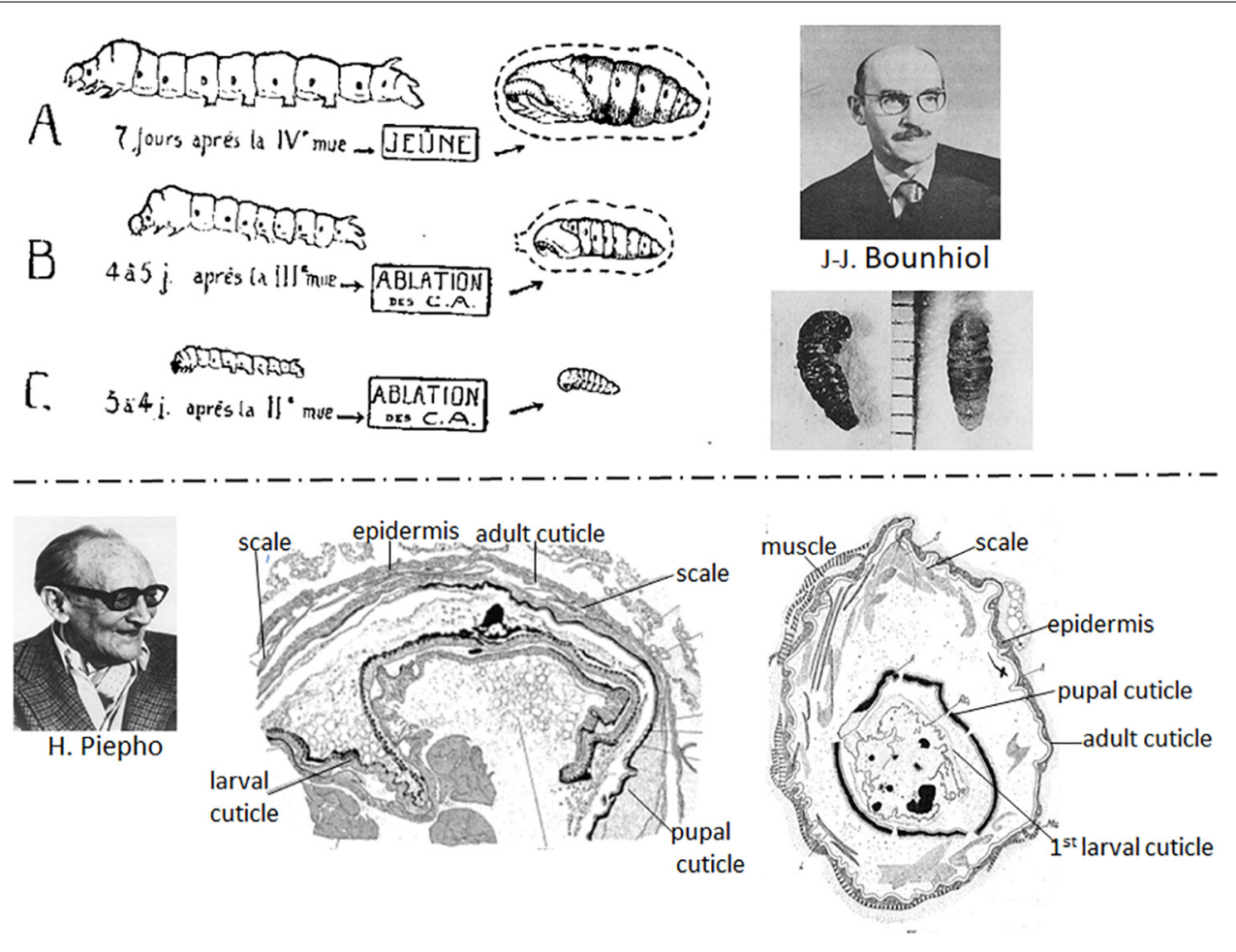

FIGURE 3 | Top: (Left) Diagram of effects of removal of the corpora allata (CA) (allatectomy) from the silkworm Bombyx mori. (A) Normal 5th instar larva and pupa; (B) allatectomized 4th instar larva formed a precocious pupa; (C) allatectomized 3rd instar larva formed a precocious pupa (figure from Bounhiol, 1938). (Right) Jean-Jacques Bounhiol (above); photo of pupae formed from allatectomized 4th (left) and 3rd (right) instar larvae (from Bounhiol, 1938) (bottom). Bottom: (Left) Hans Piepho. (Center) Result of an implant of 5th instar Galleria integument (epidermis plus cuticle) into another 5th instar Galleria larva that subsequently metamorphosed to a pupa and an adult. The implanted epidermis formed a pupal cuticle, then an adult cuticle with scales (from Piepho, 1938a). (Right) Result of an implant of $1^{\text {st }}$ instar integument into a 5th instar larva after metamorphosis of the host. The implant formed a pupal, then an adult cuticle (from Piepho, 1938b). Photo of Bounhiol from Lamy and Delsol (1980) (reproduced with permission from Elsevier Masson) and that of Piepho from Hintze-Podufal (1996) (reproduced with permission from www.schweizerbart.de/journals/entomologia). 


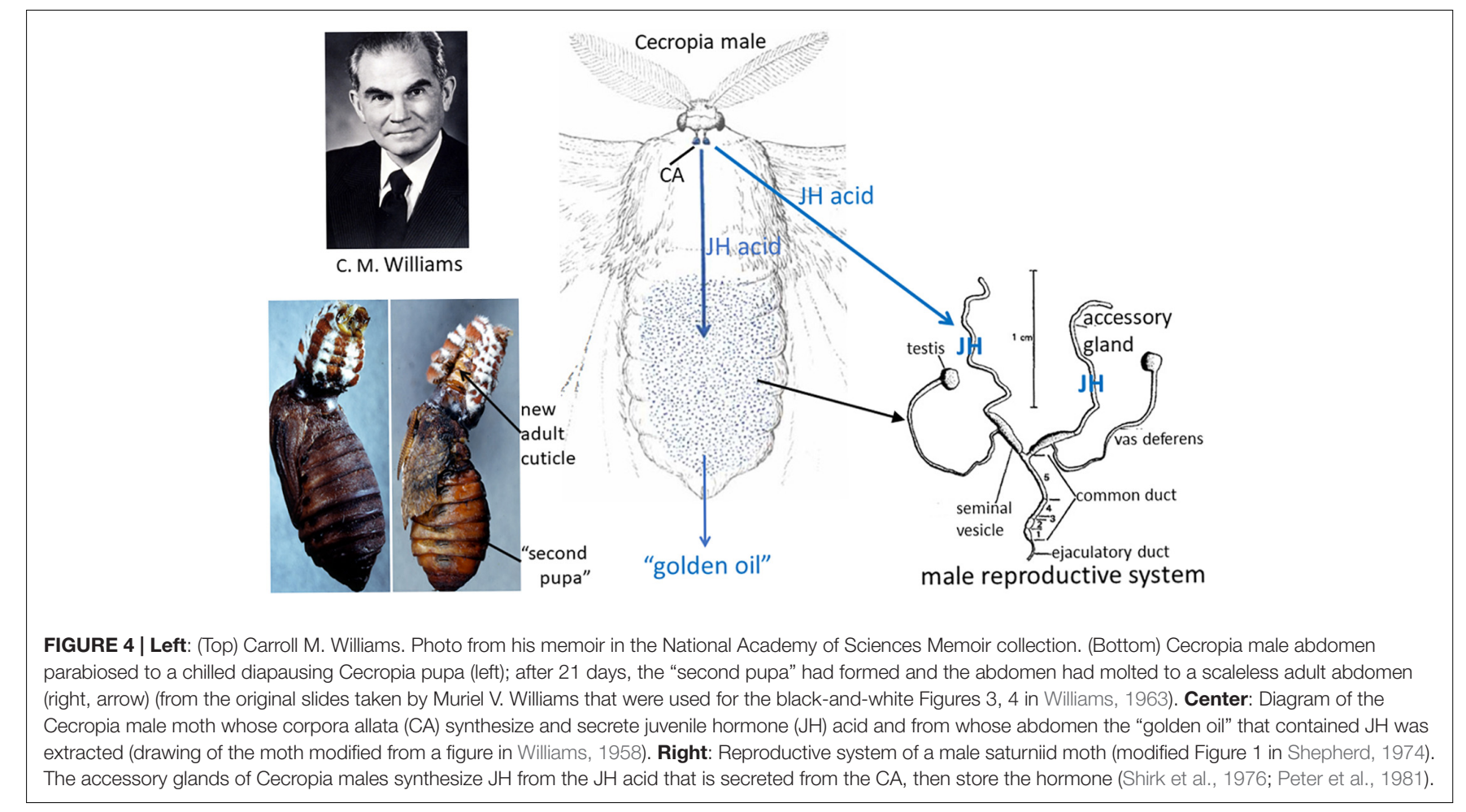

(r)

in the Diptera and Hemiptera. JH III bisepoxide (JHB3) was first identified in Drosophila melanogaster (Richard et al., 1989), and JH III skipped bisepoxide (JHSB3) was first found in the stink bug, Plautia stali (Kotaki et al., 2009; Figure 5).

\section{Insect Growth Regulators}

In his first article on the extraction of $\mathrm{JH}$ from the Cecropia male abdomen, Williams also commented on the efficacy of topical application of this extract in disrupting metamorphosis. He then suggested that "... in addition to the theoretical interest of the $\mathrm{JH}$, it seems likely that the hormone, when identified and synthesized, will prove to be an effective insecticide. This prospect is worthy of attention because insects can scarcely evolve a resistance to their own hormone" (Williams, 1956b). In 1964, Karel Sláma from Czechoslovakia came to the Williams laboratory at Harvard University to work bringing his favorite study insect, the linden bug, Pyrrhocoris apterus. Although he brought linden seeds to feed the bugs, he used glass jars containing an upright paper towel to mimic a tree to rear the insects. Surprisingly, none of the nymphs 
metamorphosed under these conditions. Initially suspecting that JH might be airborne within the Williams laboratory, Sláma reared at home some Pyrrhocoris shipped directly from Czechoslovakia but again no metamorphosis occurred; only supernumerary nymphs appeared. They then started a systematic search for a source of the hormone in the rearing conditions that resulted in the discovery that the source was the paper towels in the rearing jars (Sláma and Williams, 1965, 1966; Williams and Sláma, 1966). It proved only to be in American, not European, paper towels because the American paper towels and other paper products were made from balsam fir and European paper products were made from pine. Bowers et al. (1966) isolated and identified this "paper factor" from balsam fir as the methyl ester of todomatuic acid (juvabione) (Figure 5). Juvabione proved effective as a $\mathrm{JH}$ mimic only for the family Pyrrhocoridae, with other insects, even those in a closely related family Lygaeidae such as the milkweed bug Oncopeltus fasciatus, being unaffected. Such specificity gave rise to the hope that selective $\mathrm{JH}$ analogs might be found for prevention of metamorphosis of various pestiferous insects that would not harm beneficial insects such as honeybees.

Zoëcon founded in 1968 by Carl Djerassi, an organic chemist at Stanford University, was the first company formed to search for chemicals that had $\mathrm{JH}$ action on particular insects which they named insect growth regulators (IGRs). Methoprene (Figure 5) was first registered in 1975 by the Environmental Protection Agency as Altosid and used primarily in mosquito breeding areas as a larvicide. In treated water, larvae did not metamorphose to the adult, thus reducing the population (Staal, 1975). Today methoprene or another more potent IGR, pyriproxyfen (Figure 5), is still used in integrated pest management schemes to control mosquitoes, particularly those that are resistant to chemical insecticides (Walton and Eldridge, 2020). Methoprene is also used in combination with pyriproxyfen (Rust et al., 2016) or adulticides (Rust and Hemsarth, 2019) in flea collars and other flea products to prevent metamorphosis of flea larvae and kill the adults. Unfortunately, resistance to the IGRs has arisen (Parthasarathy et al., 2012), but combinations of IGRs or with other insecticides such as discussed above in flea control have reduced its impact.

\section{THE TOBACCO HORNWORM (Manduca sexta) AND LARVAL ENDOCRINE PHYSIOLOGY}

In the 1970s, the tobacco hornworm (M. sexta) became popular for the study of insect growth, molting and metamorphosis. Manduca thrived on a completely defined diet (Bell and Joachim, 1976) under laboratory conditions and was utilized initially by the laboratories of Carroll Williams, Fotis Kafatos, and Lynn Riddiford at Harvard University and Larry Gilbert's laboratory first at Northwestern University, then at the University of North Carolina. Jim Truman as a Junior Fellow at Harvard in the Riddiford and Williams groups showed using simple ligation experiments that the release of PTTH from the larval brain occurred during a certain time of day when the larvae were reared under a light:dark cycle (Truman, 1972; Truman and Riddiford, 1974). PTTH then activated the prothoracic glands to release ecdysone that with its biologically active metabolite, 20-hydroxyecdysone (20E) (see Riddiford et al., 2001), initiated and orchestrated the subsequent molt. The ligature experiments also appeared to indicate that $\mathrm{JH}$ necessary for larval molting was released slightly later than PTTH (Truman, 1972) and that $\mathrm{JH}$ was again necessary at the time of head capsule slippage during the molt for normal epidermal and cuticular pigmentation (Truman et al., 1973). Later Fain and Riddiford (1976) showed that the apparent delay of $\mathrm{JH}$ for the larval molt was due to the slow activation of the prothoracic glands by PTTH. The chance appearance of a black mutant larva in the Harvard tobacco hornworm colony (Safranek and Riddiford, 1975) allowed the development of a sensitive bioassay for JH (Fain and Riddiford, 1975). This assay showed that JH was present in the fourth (penultimate) instar larval hemolymph in declining amounts through the feeding and the molting periods and rose again at ecdysis to the fifth and final larval instar.

Fred Nijhout, a graduate student of Williams, subsequently showed that the final larval instar was dependent on a threshold size attained at the time of ecdysis (Nijhout and Williams, 1974a; Nijhout, 1975a). When the larva surpassed the threshold size for metamorphosis, it fed and grew in the final instar to a critical weight that started the endocrine events leading to metamorphosis (Nijhout and Williams, 1974b; Nijhout, 1975b). Subsequent studies by many on both Manduca and Bombyx have shown that these events are the decline of $\mathrm{JH}$ release by the corpora allata, the rise of a specific esterase to degrade $\mathrm{JH}$ in the hemolymph and tissues followed by the release of PTTH once the JH titer was sufficiently low (reviewed in Goodman and Granger, 2005; Hiruma and Kaneko, 2013; Nijhout et al., 2014). The subsequent release of ecdysone from the prothoracic glands was relatively small, but in the absence of $\mathrm{JH}$ caused the cessation of feeding and the onset of wandering behavior to search for a pupation site (Dominick and Truman, 1985).

During this period, Gibbs and Riddiford (1977) devised a sensitive Manduca larval assay for PTTH and showed that the region of the brain containing the lateral neurosecretory cells had the highest PTTH activity. Subsequently, Larry Gilbert's laboratory identified the pair of PTTH cells in that region (Agui et al., 1979) and studied the control of the prothoracic glands by PTTH (see reviews by Gilbert et al., 2002; Smith and Rybczynski, 2012). Much later Manduca PTTH was cloned and recombinant PTTH shown to be active (Gilbert et al., 2000; Shionoya et al., 2003), and in situ hybridization of its mRNA showed that only this pair of cells contained PTTH mRNA (Shionoya et al., 2003).

In addition, Gilbert's laboratory and Bhaskaran's laboratory at Texas A\&M University studied the control of the corpora allata by the brain (Bhaskaran et al., 1980, 1990; see also review by Goodman and Granger, 2005). Both allatotropic and allatoinhibin activities were uncovered, but the allatotropin isolated and sequenced from adult Manduca brains was inactive in larvae (Kataoka et al., 1989). 


\section{CELLULAR ACTIONS OF JUVENILE HORMONE}

\section{Early Studies}

The cellular actions of JH were first addressed by Wigglesworth $(1940 ; 1963 ; 1973)$ in his studies of its action on the abdominal epidermis of Rhodnius. He found that cells responded to the molting hormone at metamorphosis in a particular pattern within the segment and that could be blocked by $\mathrm{JH}$ given at different times. He concluded that whereas the molting hormone activates the epidermal cells to begin growth, $\mathrm{JH}$ "merely ensures [perhaps by some action at the level of genes (Wigglesworth, 1954), perhaps indirectly by some action upon the cytoplasm (Wigglesworth, 1953)], that the larval pattern is maintained among the activated epidermal cells" (Wigglesworth, 1963). Later Lawrence (1969) found that treatment of Oncopeltus with JH at a specific time in the final nymphal instar caused the formation of adult cuticle with larval pigmentation. Willis et al. (1982) extended this study to Pyrrhocoris, the Colorado potato beetle, Leptinotarsa decemlineata, and various Lepidoptera, showing that there were two effects of $\mathrm{JH}$-one causing a mosaic cuticle which has discrete patches of different stage-specific cuticle due to differing epidermal sensitivity to $\mathrm{JH}$ and the other a composite cuticle produced by a single cell which combines features of two metamorphic stages due to differing temporal $\mathrm{JH}$ sensitivity of different morphological characteristics.

\section{Control of Cellular Commitment}

The Manduca larva provided an epidermis that could be readily cultured and produce cuticle in vitro in response to the proper hormonal regimen. A new larval cuticle was synthesized by fourth instar larval epidermis when exposed to 20E immediately after explantation from an intermolt feeding larva (Riddiford et al., 1979, 1980). If, however, cultured in hormone-free media for $24 \mathrm{~h}$, then exposed to 20E, it formed a pupal cuticle (Mitsui and Riddiford, 1978; Riddiford et al., 1980). When final larval instar epidermis was exposed to a low concentration of $20 \mathrm{E}$ followed by a high concentration, thereby mimicking the prewandering and pupal molt concentrations of ecdysteroid (Bollenbacher et al., 1981), it formed a pupal cuticle (Mitsui and Riddiford, 1976, 1978). Therefore, one could ask about the direct action of JH on the epidermis under defined conditions.

The abdominal epidermis of Manduca is polymorphic in that it first makes a larval cuticle under the influence of $\mathrm{JH}$ when exposed to ecdysteroid for the penultimate and final larval molts. Then when exposed to low ecdysteroid in the absence of detectable $\mathrm{JH}$ during the pre-wandering peak of ecdysteroid, the epidermis becomes unable to produce a larval cuticle either in vivo (when implanted into a penultimate stage larva and allowed to go through final larval molt) (Riddiford, 1976, 1978) or in vitro in response to $20 \mathrm{E}$ and $\mathrm{JH}$ (Mitsui and Riddiford, 1978). Instead it produces pupal cuticle. Hence, in response to the hormonal conditions alone, a single epidermal cell can switch from producing a larval cuticle to a pupal cuticle and therefore is now pupally committed. Although the epidermal cells of beetle (T. molitor) (and lepidopteran) larvae are electrically coupled through gap junctions through which small molecules move readily (Caveney and Podgorski, 1975), the cells of the abdominal segment of Manduca respond to this ecdysteroidinduced change of commitment in a particular pattern (Truman et al., 1974; Riddiford, 1978) that turns out to be same as the cell-by-cell induction of the Bric-à-brac-Tramtrack-Broad (BTB) transcription factor Broad by 20E (Zhou and Riddiford, 2001).

In Drosophila during the molt, 20E initiates a transcription factor cascade called the "Ashburner cascade." This cascade was first defined by Ashburner et al. (1974) as a series of salivary gland chromosomal puffs (expansions of the polytene DNA strands) induced by $20 \mathrm{E}$ in vitro that corresponded to the puffs seen in vivo at the time of wandering just before and during pupariation. Many of the puffs were later found to encode transcription factors (Thummel, 1990). The same cascade of transcription factors is seen in Manduca abdominal epidermis at both the fourth-fifth larval molt and metamorphosis (summarized in Hiruma and Riddiford, 2010) with the exception that Broad is not induced at the fifth larval molt, but only at the time of the ecdysteroid peak that initiates wandering. Thus, Manduca larval abdominal epidermis proved to be an ideal system in which to study the action of $\mathrm{JH}$ at the cellular and molecular levels. As seen above, when exposed to $20 \mathrm{E}$ in the absence of $\mathrm{JH}$, this epidermis first expresses broad as it becomes pupally committed. Once committed, it henceforth only makes pupal cuticle when next confronted with a molting concentration of ecdysteroid, whether in vivo or in vitro (Hiruma and Riddiford, 2010). Once broad is activated by the ecdysteroid, its mRNA levels fluctuate during the wandering and prepupal periods directed by the levels of $20 \mathrm{E}$ present. Then after pupal ecdysis, broad mRNAs disappear from the epidermis over the first 3 days of pupal life and never reappear during the pupal-adult molt or in the adult epidermis (Zhou and Riddiford, 2002). However, when $\mathrm{JH}$ is given to the freshly ecdysed pupa, the broad transcripts reappear when the ecdysteroid titer arises for the subsequent molt and a "second pupa" rather than an adult is formed. Thus, JH prevents the ecdysteroid-induced switching on of broad in the larval epidermis and the ecdysteroid-induced switching off of broad in the pupal epidermis.

\section{Drosophila Development, JH and Stage-Specifying Transcription Factors}

To elucidate how JH acted to direct the action of ecdysteroid in the polymorphic epidermis, one had to turn to Drosophila with its wealth of genetic and molecular biological approaches. Drosophila along with the other higher Diptera has however the disadvantage for studying $\mathrm{JH}$ action on metamorphosis in that nearly all of the larval tissues except for the Malpighian tubules and the nervous system are discarded at metamorphosis. The adult head and thorax are made from imaginal discs that make larval cuticle and proliferate throughout larval life, then differentiate at metamorphosis, whereas the abdomen comes from abdominal histoblasts (Perez, 1910; Svácha, 1992; Fristrom and Fristrom, 1993). These histoblasts do not divide but make larval cuticle that lies above them during larval life. Then during the prepupal period after pupariation, they begin to 
divide. The pupal cuticle of the abdomen then is made by reprogrammed larval epidermal cells and histoblasts. After head eversion to form the intact pupa inside the puparium, the proliferated histoblasts spread out from their nests in each abdominal segment, displacing the larval epidermal cells to form the adult epidermis (Ninov et al., 2007, 2009). The displaced larval cells are then engulfed by phagocytic hemocytes (Williams and Truman, 2005). When the ecdysteroid titer rises for the adult molt beginning about $18 \mathrm{~h}$ after pupariation (Handler, 1982), the imaginal epidermal cells first respond by undergoing adult commitment and patterning, then as the ecdysteroid titer declines form the adult cuticle beginning about 48-52 h after pupariation (Fristrom and Fristrom, 1993; Zhou and Riddiford, 2002; Ninov et al., 2009).

Normally Broad is present in the histoblasts and their derivatives until about $30 \mathrm{~h}$ after pupariation, then disappears (Zhou and Riddiford, 2002). By contrast, when JH is applied at the time of pupariation, the pupa appears normal but the resultant adult is a mosaic of a normal head and thorax and a pupal abdomen (Ashburner, 1970; Postlethwait, 1974). Under these conditions, Broad persists in the adult abdominal epidermis throughout adult development (Zhou and Riddiford, 2002). Furthermore, when broad-Z1 was overexpressed in the whole animal using a heat shock GAL4 promoter between 30 and $36 \mathrm{~h}$ and again at about $48 \mathrm{~h}$ after pupariation, a second pupa was formed, indicating that the structures developing from the imaginal discs as well as from the histoblasts were capable of forming pupal cuticle. Thus, the presence of Broad in the cell allows it to make pupal cuticle in response to ecdysteroid and prevents the production of adult cuticle.

During adult development, ecdysone and 20E rise in the absence of $\mathrm{JH}$, and the adult-specifying transcription factor E93 appears (Ureña et al., 2014, 2016). Uyehara et al. (2017) have recently shown that E93 directly acts on the chromatin structure in the enhancers of specific genes, opening up some adult-specific genes such as nubbin (important in wing vein formation) for activation and closing the chromatin on others such as broad, thus suppressing its expression. Broad and E93 are pupal- and adult-specifying transcription factors respectively throughout the Holometabola (Truman and Riddiford, 2019; Bellés, 2020) and thus fulfill the prediction of Williams and Kafatos (1971) that there are three master regulatory genes that successively activate the larval, pupal, and adult gene sets as metamorphosis proceeds. The idea that the unique features of the larva, pupa, and adult were the results of stage-specific gene sets was nullified by the finding that the same cuticle gene was expressed in the epidermis of two different metamorphic stages to produce a particular type of cuticle (Willis, 1986). This finding however does not negate the hypothesis that there are master regulatory genes that dictate the stage. The stage-specifying transcription factors Broad (pupal) and E93 (adult) along with Krüppel homolog $1(\mathrm{Kr}-$ h1) in the larva (see below) that regulate each stage and each other (Truman and Riddiford, 2019; Bellés, 2020) seem to be the long-sought regulators.

Williams and Kafatos (1971) also postulated that there is a larval master regulatory gene. $K r$-h1 may be such a gene. Although initially discovered in Drosophila as important for metamorphosis (Pecasse et al., 2000), Kr-h1 is present throughout the insects including the primitive firebrat, Thermobia domestica (Konopova et al., 2011), and is necessary to prevent precocious metamorphosis (Minakuchi et al., 2009; Lozano and Belles, 2011). Kr-h1 appears in the embryo at the time that $\mathrm{JH}$ appears and is present throughout larval life, then disappears during metamorphosis to the pupa (see review by Truman and Riddiford, 2019). The presence of JH ensures that $\mathrm{Kr}$-h1 will appear when $20 \mathrm{E}$ rises for the larval molt and may stabilize Kr-h1 during the larval intermolt period. Kr-h1 disappears at the onset of metamorphosis only to reappear during the molt to the pupa when ecdysteroids again are acting in the presence of $\mathrm{JH}$ to prevent adult development of imaginal disc derivatives, the extent of which depends on the species studied. See, for example, the pupal-adult intermediate formed after allatectomy of the Cecropia prepupa (Williams, 1961) versus the normal pupa formed by allatectomized Bombyx or Galleria larvae (Bounhiol, 1938; Piepho, 1942). However, Kr-h1 does not appear to be a nymph- or larval-specifying factor since its suppression by RNAi in the embryo does not prevent the production of a nymph or larva (Smykal et al., 2014). Instead, the role of $\mathrm{Kr}$-h1 is likely its repression of the expression of the adult-specifying E93 as is seen in both the hemimetabolous cockroach, Blattella germanica (Belles and Santos, 2014; Ureña et al., 2016) and the holometabolous Drosophila and flour beetle, Tribolium castaneum (Ureña et al., 2016). This role of $\mathrm{Kr}$-h1 has been emphasized in naming the molecular pathway underlying the "status quo" action of JH in metamorphosis the Met-Kr-h1-E93 (MEKRE93) pathway (Belles and Santos, 2014).

\section{JUVENILE HORMONE RECEPTOR}

In 1967 when JH was identified as a sesquiterpenoid (Röller et al., 1967), hormones were thought to be only steroids, peptides or proteins with intracellular receptors for the steroids and membrane receptors for the peptides and proteins. The sesquiterpenoid nature of $\mathrm{JH}$ allows it to enter the cell (Mitsui et al., 1979) but also allows it to interact with the membrane (Davey, 1996, 2000; Wyatt and Davey, 1996; Goodman and Cusson, 2012). The search for these JH receptors turned out to be long and tortuous and is not over yet.

\section{Intracellular Receptors JP29}

The "status quo" action of JH during larval life is assumed to be intracellular since it directs nuclear ecdysteroid action during the larval molts and must be absent for ecdysteroids to initiate metamorphosis. A JH binding protein (JHBP) was isolated from Manduca larval hemolymph that bound $\mathrm{JH}$ and protected it from the hemolymph esterases but not the $\mathrm{JH}$-specific esterase that appeared once the larva attained the critical weight for metamorphosis (reviewed by Goodman and Cusson, 2012). JHBP is also thought to have other functions including presentation of JH to the cell (see review by Goodman and Cusson, 2012). However, studies in vitro showed that $\mathrm{JH}$ I alone was just as effective as the combination of JH I and JHBP in the culture 
medium in preventing the 20E-induced pupal commitment of the Manduca abdominal epidermis (Riddiford, 1978).

The search for the intracellular $\mathrm{JH}$ receptor in Manduca utilized photoaffinity-labeled $\mathrm{JHs}$ and $\mathrm{JH}$ analogs (synthetic compounds that could be photo-cross-linked to cellular protein(s) to which they bound to allow the subsequent isolation of the protein) (Prestwich et al., 1994). This search yielded a $29 \mathrm{kDa}$ nuclear protein (JP29) which at first was thought to be the JH receptor (Palli et al., 1994). Later studies by Charles et al. (1996) showed that the apparent tight, specific binding of JH I to JP29 was an artifact of a co-purifying esterase that removed the tritiated ester group of JH I used to monitor that binding. Moreover, JP29 was found to bind to the insecticyanin granules in the epidermis and to be regulated by $20 \mathrm{E}$ during a larval molt but not after pupal commitment (Shinoda et al., 1997). The role of JP29 in the epidermis is unknown.

\section{USP}

Ultraspiracle (USP) was shown to be the heterodimeric partner of the ecdysone receptor (EcR) necessary for the action of $20 \mathrm{E}$ in tissues, but $20 \mathrm{E}$ only bound specifically and tightly to EcR (see review by Riddiford et al., 2001). The usp null mutant in Drosophila initiates the molt normally at the end of the first instar and makes the second instar cuticle, but is unable to ecdyse (Oro et al., 1992). Rescue to the mid-third instar was afforded by one heat shock pulse of usp in the first instar (apparently due to the persistence of USP protein in the larva through the onset of the second instar molt) (Hall and Thummel, 1998). Thereafter, however, the larva entered a "stationary phase" instead of wandering at the expected time of the onset of metamorphosis. Twenty-four hours later, a new cuticle composed of both larval and pupal cuticle proteins covered the posterior region of the body, but the anterior region had only partially everted imaginal discs, and death ensued. Interestingly, the onset of glue protein synthesis in the salivary glands necessary for gluing the puparium to the substrate at the time of pupariation occurred normally at the mid-third instar transition but the glue was not secreted nor did the glands later die as normally occurs. Thus, it appears that USP is needed as a partner for EcR during the larval molts when the ecdysteroid titer is high but is not essential for low ecdysteroid action that causes glue protein synthesis. This latter action may be due to the ecdysteroid sitting on the EcR and causing derepression (Schubiger et al., 2005).

In 1997, Jones and Sharp (1997) found that recombinant Drosophila USP specifically bound JH III and JH III acid [the natural $\mathrm{JH}$ and its acid metabolite found in Drosophila third (final) larval instar hemolymph (Jones et al., 2013)] and suggested that it might be the JH receptor in the larva (Jones and Sharp, 1997; Jones et al., 2006). Unfortunately, the binding of JH III to USP showed about 100-fold lower affinity than one would expect for a hormone receptor. Later studies showed that the potential binding pocket of USP was filled by an unknown phospholipid under in vivo conditions (Billas et al., 2001; Sasorith et al., 2002). Also, a Drosophila USP-GFP reporter construct that was properly activated by $20 \mathrm{E}$ in explanted larval brains and salivary glands was not responsive to JH III alone nor to a combination of $20 \mathrm{E}$ and $\mathrm{JH}$ III (Beck et al., 2009). Only when the explants were pretreated with JH III before adding the $20 \mathrm{E}$ did JH III have an effectthat of reducing the activation produced by $20 \mathrm{E}$. These and other studies (reviewed in Riddiford, 2008) strongly suggested that USP was not the $\mathrm{JH}$ receptor during larval life.

Instead USP may be the receptor for methyl farnesoate during the mid-third instar transition in Drosophila when methyl farnesoate is the predominant juvenoid in the hemolymph (Jones et al., 2013) and can be converted to JH bis-epoxide (Wen et al., 2015; see Figure 5 for structures of methyl farnesoate and $\mathrm{JH}$ bis-epoxide). The Jones group found that USP bound methyl farnesoate with an affinity similar to that of the binding of the retinoid X receptor (RXR) to its ligand 9-cis-retinoic acid and that point mutations of USP in residues in the apparent ligand binding pocket decreased this binding 4-10-fold. The $u s p^{2}$ null mutant could be rescued by USP through metamorphosis but not by the mutant USPs, which instead showed abnormal development at the time of wandering. Thus, the mutated USP apparently could not bind the circulating methyl farnesoate to allow normal metamorphic development although it did not interfere with the normal first and second instar molts. What exact role the methyl farnesoate-USP complex is playing at the onset of metamorphosis remains a mystery that needs exploring.

\section{Methoprene-Tolerant (Met) Encodes the JH Receptor}

In 1986, Tom Wilson took a different approach to look for the $\mathrm{JH}$ receptor. He mutagenized Drosophila with ethyl methanesulfonate, then reared the larvae on diet containing a high concentration of the $\mathrm{JH}$ analog methoprene (Wilson and Fabian, 1986; Figure 6A, top). Screening with methoprene or JH III that prevents metamorphosis of the abdomen (see above section for $\mathrm{JH}$ effects on Drosophila) yielded a mutant that was about 100 -fold more resistant to $\mathrm{JH}$ than the parental wildtype, which they named Methoprene-tolerant (Met). Because increased levels of $\mathrm{JH}$ were needed in the Met mutant for both its metamorphic and reproductive effects, they suggested that the Met protein might be involved in $\mathrm{JH}$ reception.

This hypothesis was not confirmed until Konopova and Jindra (2007) showed that Met expression was necessary in the flour beetle, T. castaneum, to prevent premature metamorphosis. Suppression of Met expression by RNAi in third or fourth instar larvae yielded premature pupation after the fifth or sixth instar (of a total of 7 larval instars) (Figure 6A, bottom). A few of these survived to form miniature adults. Moreover, neither methoprene nor JH III application was effective to cause the formation of "second pupae" by Tribolium pupae that had been given Met RNAi. Thus, the loss of Met in Tribolium prevented the usual metamorphic responses to $\mathrm{JH}$ and therefore fit the criteria for a $\mathrm{JH}$ receptor.

As discussed above, the higher Diptera have an extreme form of metamorphosis whereby the larval body is discarded except for the nervous system and the Malpighian tubules; and the adult arises from imaginal cells and discs that have proliferated during larval life or in the case of the abdominal histoblasts during the prepupal period (Perez, 1910; Fristrom and Fristrom, 1993). In Drosophila larvae, JH is present and declines before metamorphosis (Bownes and Rembold, 1987; Sliter et al., 1987) but seems to have no role in larval life. Dietary JH caused only 


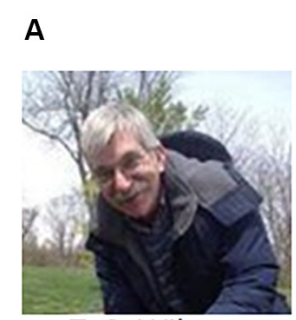

T. G. Wilson
Drosophila abdominal sternites after larvae were fed methoprene
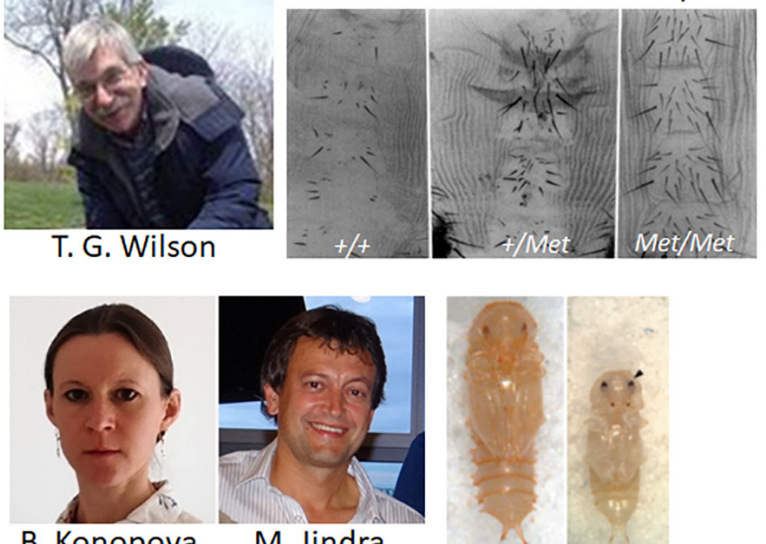

B. Konopova
M. Jindra

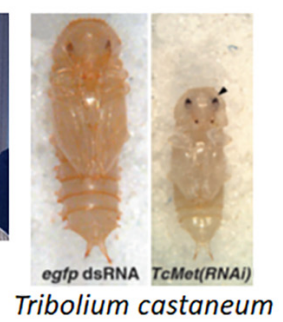

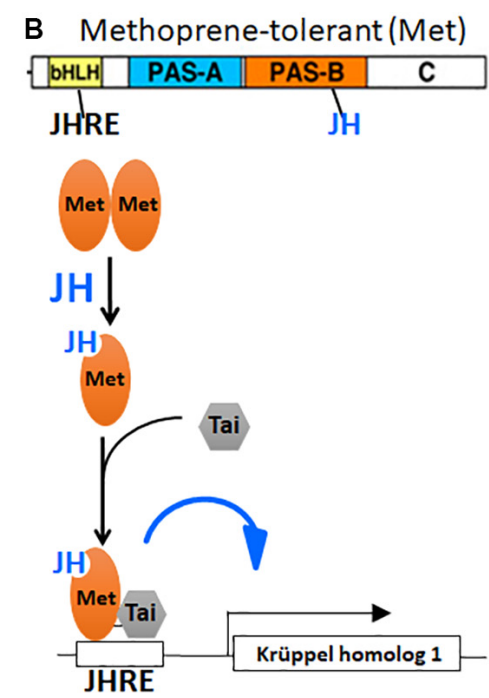

FIGURE 6 | (A) Top: (Left) Tom Wilson (photo was taken by Emily Wilson and used with her permission). The adult abdominal sternites of the Methoprene-tolerant $\left(\mathrm{Met}^{+}\right)$mutant of Drosophila melanogaster after the larvae fed on diet containing methoprene (modified from Figure 2 of Wilson and Fabian, 1986). +/+, homozygous wild type; +/Met, heterozygous Met mutant; Met/Met, homozygous Met mutant. Bottom: Barbora Konopova and Marek Jindra and the precocious pupa they obtained after giving Met RNAi to a 4th instar larva of Tribolium castaneum (right) compared with a normal pupa that formed after egfp RNAi had been given to a 4th instar larva (left) (modified from Figure 3 in Konopova and Jindra, 2007). Photos of Barbora Konopova from her Research Gate file (used with her permission) and of Marek Jindra taken by Masako Asahina (used with Dr. Jindra's permission). (B) Top: Cartoon of the Met protein showing its various domains: bHLH, basic helix-loop-helix domain; the Period-Arylhydrocarbon receptor nucleotide translocator-Single-minded (PAS) A and B domains; the C terminal domain. The bHLH domain binds to the juvenile hormone (JH) response element (JHRE) on the target gene promoter; JH binds to the Pas B domains of Met (Charles et al., 2011) and Germ cell-expressed (Gce) [the paralog of Met (Baumann et al., 2010)] (Bittova et al., 2019). Bottom: Cartoon of events occurring when JH enters a target cell. The unliganded Met is thought to exist as a homodimer (Godlewski et al., 2006). When JH is present, it binds to Met causing the dissociation of the dimer and the binding of Taiman (Tai) to Met, then both Tai and Met bind to the JHRE on the promoters of Krüppel homolog 1 (Kr-h1) and other JH target genes (Jindra et al., 2015a).

a prolongation of the final larval instar followed by a normal appearing puparium that developed to the pharate adult but did not eclose (Bryant and Sang, 1968; Riddiford and Ashburner, 1991). These pharate adults had abdominal defects similar to those found when $\mathrm{JH}$ was applied at pupariation (Ashburner, 1970; Postlethwait, 1974) as well as nervous system defects (Restifo and Wilson, 1998; Riddiford et al., 2010, 2018). In contrast to other holometabolous insects, when Drosophila larvae were genetically allatectomized by overexpressing cell death genes in the corpora allata, the larvae formed normal puparia but died at or shortly after head eversion to the pupa (Liu et al., 2009; Riddiford et al., 2010). The discrepancy between the Met null mutant surviving to the adult and the death of the allatectomized pupa was found to be due to the existence of a second, closely related gene named germ cell-expressed (gce) (Baumann et al., 2010). Met-gce double mutants die at head eversion (Abdou et al., 2011) just as allatectomized prepupae do. Met and gce are paralogous genes with gce representing the ancestral gene (Baumann et al., 2010).

Methoprene-tolerant is a member of the basic-helix-loophelix (bHLH)-Period (per)-Aryl hydrocarbon receptor nuclear translocator (Arnt)-Single-minded (sim) (PAS) domain family of transcription factors (Figure 6B). Charles et al. (2011) found that recombinant Met bound both methoprene and JH III with high affinity in the PAS-B domain. Subsequent studies have shown that the Met-JH complex heterodimerizes with a cofactor Taiman [also known as steroid response coactivator
(SRC) and $ß F t z-F 1$ Interacting Steroid Receptor Coactivator (FISC)] and forms a complex that binds to a JH-response element on the mosquito early trypsin gene ( $\mathrm{Li}$ et al., 2011; Jindra et al., 2015a; Liu et al., 2018) and on the $K r$-h1 gene in Tribolium and Blattella (Zhang et al., 2011; Lozano et al., 2014). Both Met and Gce bind JH III and methyl farnesoate as well as the $\mathrm{JH}$ analogs methoprene and pyriproxyfen, and this binding is necessary for the induction of $\mathrm{Kr}-\mathrm{h} 1$ in Drosophila larvae (Jindra et al., 2015b; Wen et al., 2015; Bittova et al., 2019).

\section{Membrane Receptor}

Based on studies with Rhodnius follicular cell epithelium (Davey and Huebner, 1974; Davey, 1996), Davey postulated that JH has a membrane receptor for its role in oocyte maturationincreasing the intercellular spaces so that vitellogenin can enter the oocyte. This receptor appeared to activate the sodiumpotassium ATPase ("sodium pump") in the cells causing them to lose water and consequently shrink to create the intercellular spaces (termed "patency"). Abortive attempts were made to isolate this receptor (Davey, 1996). Recently, Jing et al. (2018) showed in the locust that $\mathrm{JH}$ causes the phosphorylation of the follicular cell Na-K-ATPase, thus activating it and causing increased patency.

Juvenile hormone activation of the early trypsin gene in the mosquito, Aedes aegypti, involves the activation of the phospholipase $\mathrm{C}$ pathway and the phosphorylation of both Met 
and Tai which enhances the binding of Met-Tai intracellular dimer on the promoter of the early trypsin gene (Liu et al., 2015; Ojani et al., 2016). How this activation of the membrane phospholipids occurs is still unknown.

\section{QUESTIONS FOR THE FUTURE}

\section{Why Is Not JH Required for the First Two Instars in Insects?}

In his early experiments, Wigglesworth (1934) parabiosed a decapitated fed first instar nymph to a fed final instar nymph that had been decapitated after the critical period for the adult molt. The first instar nymph molted to a miniature adult with adult abdominal pigmentation and patterning, precocious genitalia and rudimentary wings. Similarly, Piepho (1938b) showed that an integumental (epidermis and overlying cuticle) implant from a first instar Galleria larva in a final instar larva formed both a pupal cuticle and an adult cuticle with scales when the host metamorphosed (Figure 2, bottom right). Thus, the cells of early instar animals are capable of forming adult structures when exposed to the proper hormonal environments. Yet under normal conditions in the presence of $\mathrm{JH}$ in the immature stages, they form nymphal (Rhodnius) or larval (Galleria) structures at the molt.

Recent studies have shown, however, that $\mathrm{JH}$ is not necessary for progress through the first and second instars after hatching (Daimon et al., 2012; see also reviews by Jindra, 2019; Truman and Riddiford, 2019; Bellés, 2020). Although the corpora allata begin secreting $\mathrm{JH}$ about two-thirds of the way through embryogenesis and continue at least to hatching, neither Met nor $\mathrm{Kr}-\mathrm{h} 1$ is necessary for development of the first or second instar larvae or nymphs respectively of the silkworm Bombyx and the linden bug, Pyrrhocoris (Smykal et al., 2014; Daimon et al., 2015). Only in the third instar does one begin to see the effects of the absence of $\mathrm{JH}$ in terms of the precocious appearance of adult characters in Pyrrhocoris or of broad mRNA in Bombyx. In the latter without the $\mathrm{JH}$ receptor Met, most larvae die in the molt to the third instar with mosaic patches of larval and pupal cuticle (Daimon et al., 2015). To resolve this conundrum of the lack of a requirement for $\mathrm{JH}$ for the first two instars, Daimon et al. (2015) have proposed that for metamorphosis to occur requires the appearance of a "competence factor" which is necessary to induce broad expression. Once this factor appears, the presence of $\mathrm{JH}$ at the time of ecdysteroid rise for the molt is necessary to keep broad suppressed.

Besides its "status quo" action during ecdysteroid-induced molts, JH also is essential for maintaining proliferative growth and suppressing morphogenesis in imaginal cells and discs during the intermolt growth periods of Lepidoptera (Truman et al., 2006). Morphogenetic growth in preparation for metamorphosis normally begins in the final instar when the $\mathrm{JH}$ titer declines after the larva has attained the critical weight for metamorphosis (Zhou and Riddiford, 2001; MacWhinnie et al., 2005; Allee et al., 2006). At this time, broad mRNA appears in the imaginal cells followed sometime later by the onset of the morphogenetic proliferation. The onset of broad expression only requires sucrose feeding, but proliferation requires protein as well (MacWhinnie et al., 2005; Truman et al., 2006; Suzuki et al., 2013). The switch from proliferative growth in the early instars to morphogenetic growth in the final instar requires only the decline of $\mathrm{JH}$ and can occur in the absence of ecdysteroid (Truman et al., 2006). However, it requires the presence of a "metamorphosis initiation factor" which is dependent on nutrient input and may be similar to the "competence factor" seen in third instar Bombyx larvae (Daimon et al., 2015; Inui and Daimon, 2017). The nutrient input appears to trigger insulin signaling that is necessary for the wing discs to become competent to metamorphose (Koyama et al., 2008; Suzuki et al., 2013).

The requirement for either a nymph or a larva to undergo two feeding instars before metamorphosis holds throughout the insects (Truman, 2019; Truman and Riddiford, 2019). Once they enter the third feeding instar, $\mathrm{JH}$ is then necessary to prevent metamorphosis until a threshold size to form a viable adult is achieved. The identities of the "competence factor" for metamorphosis and the "metamorphosis initiation factor" and the necessary interactions between nutrition and hormones to achieve this threshold size are critical problems yet to be solved.

\section{Why Do Drosophila Imaginal Discs and Histoblasts Differ in Their Response to JH?}

In higher Diptera, metamorphosis entails the loss of all larval tissues except for the nervous system and the Malpighian tubules (Perez, 1910; Fristrom and Fristrom, 1993). As discussed above in the section on Drosophila development, the adult develops externally from the imaginal discs and the abdominal histoblasts and internally from imaginal cells associated with larval tissues. For the epidermis, only the abdominal histoblasts are sensitive to $\mathrm{JH}$, and that sensitivity occurs during their proliferation during the prepupal period. The histoblasts contain both $\mathrm{JH}$ receptors, Met and Gce (Baumann et al., 2017). Normally they begin to express broad mRNA during the late third instar and continue to do so during their proliferation and spreading until about $24 \mathrm{~h}$ after pupariation (Zhou and Riddiford, 2002). Broad protein then disappears from these cells by $30 \mathrm{~h}$ after pupariation. When JH was applied at pupariation, Broad protein remained in the abdominal epidermis at least until $72 \mathrm{~h}$ after pupariation and these cells make pupal cuticle rather than adult cuticle (Zhou and Riddiford, 2002). Thus, JH seems to be most effective on adult abdominal differentiation when given during the time of histoblast proliferation, but why this is so remains mysterious.

Juvenile hormone has no effect on the metamorphosis of Drosophila imaginal discs, even when fed to larvae throughout larval life (Riddiford and Ashburner, 1991) or when given at the time of pupariation or early during the prepupal period (Ashburner, 1970; Postlethwait, 1974). The discs contain only one of the two JH receptors, Met, albeit at low levels; Gce has not been detected in any (Baumann et al., 2017). They however contain the necessary cofactor Taiman. Yet even 
when gce or gce and Met were overexpressed in the larval wing disc, $\mathrm{JH}$ in the diet did not prevent the subsequent metamorphosis of the disc to a normal adult structure (Baumann et al., 2017). This result suggests that the lack of $\mathrm{JH}$ effects on imaginal discs is not due to the lack of $\mathrm{JH}$ receptors.

For imaginal disc structures, there are two critical periods of adult development: (1) about 30-36 h after pupariation, when morphogenesis of adult hairs and bristles occurs; and (2) about $48-52 \mathrm{~h}$ after pupariation just before adult cuticle is deposited (Fristrom and Fristrom, 1993). Timed overexpression of broad during these two periods was sufficient to cause the head and thoracic structures to form a "second pupa" (Zhou and Riddiford, 2002), indicating that these imaginal cells can make pupal cuticle. These experiments also suggested that Broad had to be present for pupal differentiation to occur. But why exogenous $\mathrm{JH}$ causes high re-expression of Broad in the developing adult abdominal epidermis and only traces of it in the developing adult head and thorax (Zhou and Riddiford, 2002) remains an enigma.

Importantly, when $\mathrm{JH}$ was applied at pupariation, $\mathrm{Kr}$ h1 was expressed in the developing adult legs and eyes unlike its lack of expression at this time in control flies (Minakuchi et al., 2008). Thus, these discs can respond to the $\mathrm{JH}$ by maintaining $\mathrm{Kr}-\mathrm{h} 1$ expression but they still undergo metamorphosis. Since they differentiated into normal adult structures, these discs presumably express E93. This presumed E93 expression is counter to the suppression of E93 by $\mathrm{Kr}$-h1 as is normally seen in other species (Belles and Santos, 2014; Ureña et al., 2016). Further elucidation of the interaction of $\mathrm{JH}, \mathrm{Kr}-\mathrm{h} 1$, Broad, and E93 in different Drosophila tissues during development and metamorphosis is clearly needed.

\section{How Is the Secretion of JH Regulated?}

Over the years, we have learned much about how the synthesis and secretion of $\mathrm{JH}$ is regulated in both immature insects and adults by hormones (neuropeptides, ecdysteroids, and JH itself) and nutritional signals (see reviews by Stay and Tobe, 2007; Goodman and Cusson, 2012; Hiruma and Kaneko, 2013; Marchal et al., 2013; Noriega, 2014; Santos et al., 2019; Bendena et al., 2020). The mechanisms involved in this regulation such as the role of microRNAs are only beginning to be studied (Bendena et al., 2020). Particularly important is a deeper understanding of this regulation by environmental (both internal and external) signals in the role of $\mathrm{JH}$ in the control of polyphenisms ranging from pigmentary changes to organization of insect societies (Nijhout, 1995; Miura, 2019).

\section{OTHER ROLES OF JH}

Juvenile hormone has a myriad of actions in insects beyond its well-known effects on insect metamorphosis and reproduction. This diversity of action may stem at least partially from its uniqueness among animal hormones in terms of its chemical structure as a sesquiterpenoid and its receptor as a member of the bHLH family of transcription factors. The immediate precursor of $\mathrm{JH}$, methyl farnesoate, is found in the Crustacea which are ancestral to the insects and is involved in reproductive maturation and possibly in early development (Nagaraju, 2011; Qu et al., 2018; Miyakawa et al., 2018). In the crustacean Daphnia magna where methyl farnesoate is necessary for environmental male sex determination (Olmstead and Leblanc, 2002; LeBlanc and Medlock, 2015; Toyota et al., 2015), the Met receptor for methyl farnesoate was found to differ in only one amino acid in its binding pocket from the insect Tribolium Met

\section{Milestones in Juvenile Hormone Research}

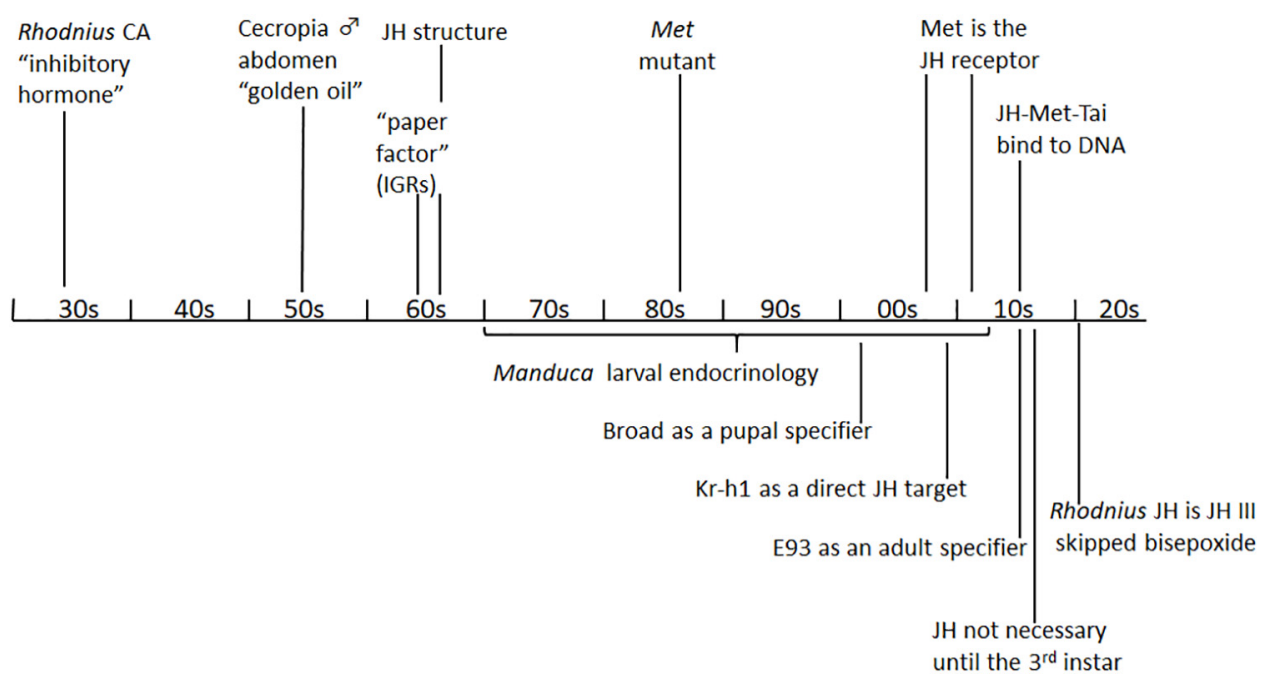

FIGURE 7 | Summary diagram of milestones in juvenile hormone research. See text for details. CA, corpus allatum; IGR, insect growth regulator; JH, juvenile hormone; Kr-h1, Krüppel homolog 1; Met, Methoprene-tolerant; Tai, Taiman. 
(Miyakawa et al., 2013, 2018). This difference was found to favor the binding affinity for methyl farnesoate over JH III.

\section{SUMMARY}

Figure 7 shows the major milestones in the progress of research on JH from the time of its discovery by Wigglesworth in the 1930s to the present which have been detailed in this short review. This progress has been from the phenomenological to the underlying molecular basis of its action. The JH I and II of Cecropia were identified in 1967 and 1968, then the JH III of most other insects as well as JH 0 in Lepidoptera and JH III bis-epoxide in the higher Diptera were identified in the 1970s and 1980s, but it was not until 2020 that the JH of Rhodnius was shown to be JHSB3 (Villalobos-Sambucaro et al., 2020). Now that we have the receptors and know something about its downstream effectors, we should be able to delve further into the molecular modes of

\section{REFERENCES}

Abdou, M. A., Heb, Q., Wen, D., Zyaan, O., Wang, J., Xu, J., et al. (2011). Drosophila Met and Gce are partially redundant in transducing juvenile hormone action. Insect Biochem. Mol. Biol. 41, 938-945. doi: 10.1016/j.ibmb.2011.09.003

Agui, N., Granger, N. A., Gilbert, L. I., and Bollenbacher, W. E. (1979). Cellular localization of the insect prothoracicotropic hormone: in vitro assay of a single neurosecretory cell. Proc. Natl. Acad. Sci. U.S.A. 76, 5694-5698. doi: 10.1073/ pnas.76.11.5694

Allee, J. P., Pelletier, C. L., Fergusson, E. K., and Champlin, D. T. (2006). Early events in adult eye development of the moth, Manduca sexta. J. Insect Physiol 52, 450-460. doi: 10.1016/j.jinsphys.2005.12.006

Aminoff, M. J. (2017). The life and legacy of Brown-Séquard. Brain 140, 15251532.

Ashburner, M. (1970). Effects of juvenile hormone on adult differentiation of Drosophila melanogaster. Nature 227, 187-189. doi: 10.1038/227 $187 \mathrm{a} 0$

Ashburner, M., Chihara, C., Meltzer, P., and Richards, G. (1974). Temporal control of puffing activity in polytene chromosomes. Cold Spring Harb. Symp. Quant. Biol. 38, 655-662. doi: 10.1101/sqb.1974.038.01.070

Baumann, A., Fujiwara, Y., and Wilson, T. G. (2010). Evolutionary divergence of the paralogs Methoprene tolerant (Met) and germ cell expressed ( $g c e$ ) within the genus Drosophila. J. Insect Physiol. 56, 1445-1455. doi: 10.1016/j.jinsphys.2010. 05.001

Baumann, A. A., Texada, M. J., Chen, H. M., Etheredge, J. N., Miller, D. L., Picard, S., et al. (2017). Genetic tools to study juvenile hormone action in Drosophila. Sci. Rep. 7:2132. doi: 10.1038/s41598-017-02264-4

Beck, Y., Delaporte, C., Moras, D., Richards, G., and Billas, I. M. (2009). The ligandbinding domains of the three RXR-USP nuclear receptor types support distinct tissue and ligand specific hormonal responses in transgenic Drosophila. Dev. Biol. 330, 1-11. doi: 10.1016/j.ydbio.2008.12.042

Bell, R. A., and Joachim, F. G. (1976). Techniques for rearing laboratory colonies of tobacco hornworms and pink bollworms. Ann. Entomol. Soc. Am. 69, 365-373. doi: 10.1093/aesa/69.2.365

Bellés, X. (2020). Insect Metamorphosis: From Natural History to Regulation of Development and Evolution. New York, NY: Academic Press.

Belles, X., and Santos, C. G. (2014). The MEKRE93 (Methoprene tolerant-Krüppel homolog 1-E93) pathway in the regulation of insect metamorphosis, and the homology of the pupal stage. Insect Biochem. Mol. Biol. 52, 60-68. doi: 10.1016/ j.ibmb.2014.06.009

Bendena, W. G., Hui, J. H. L., Sang, I. C.-S., and Tobe, S. S. (2020). Neuropeptide and microRNA regulators of juvenile hormone production. Gen. Comp. Endocrinol. 295:113507. doi: 10.1016/j.ygcen.2020.113507

Bergot, B. J., Jamieson, G. C., Ratcliff, M. A., and Schooley, D. A. (1980). JH Zero: new naturally occurring insect juvenile hormone from developing embryos action of this unique hormone that controls so many aspects of the insect's life history.

\section{AUTHOR CONTRIBUTIONS}

LR was the sole author of this manuscript.

\section{ACKNOWLEDGMENTS}

I thank Dr. James Truman for the drawings in Figures 1, 2, for helpful discussion during the writing of this manuscript, and critical comments on the article as a whole; Dr. Bronislaw Cymborowski for comments on Stefan Kopec; Drs. Xavier Belles and Judy Willis for critical comments on the final manuscript; and Dr. Belles for providing Figure 5.

of the tobacco hornworm. Science 210, 336-338. doi: 10.1126/science.210.44 67.336

Bhaskaran, G., Dahm, K. H., Barrera, P., Pacheco, J. L., Peck, K. E., and MuszynskaPytel, M. (1990). Allatinhibin, a neurohormonal inhibitor of juvenile hormone biosynthesis in Manduca sexta. Gen. Comp. Endocrinol. 78, 123-136. doi: 10.1016/0016-6480(90)90053-o

Bhaskaran, G., Jones, G., and Jones, D. (1980). Neuroendocrine regulation of corpus allatum activity in Manduca sexta: sequential neurohormonal and nervous inhibition in the last-instar larva. Proc. Natl. Acad. Sci. U.S.A. 77, 4407-4411. doi: 10.1073/pnas.77.8.4407

Billas, I. M., Moulinier, L., Rochel, N., and Moras, D. (2001). Crystal structure of the ligand-binding domain of the ultraspiracle protein USP, the ortholog of retinoid X receptors in insects. J. Biol. Chem. 276, 7465-7474. doi: 10.1074/ jbc.m008926200

Bittova, L., Jedlicka, P., Dracinsky, M., Kirubakaran, P., Vondrasek, J., Hanus, R., et al. (2019). Exquisite ligand stereoselectivity of a Drosophila juvenile hormone receptor contrasts with its broad agonist repertoire. J. Biol. Chem. 294, 410-423. doi: 10.1074/jbc.ra118.005992

Bollenbacher, W. E., Smith, S. L., Goodman, W., and Gilbert, L. I. (1981). Ecdysteroid titer during larval-pupal-adult development of the tobacco hornworm, Manduca sexta. Gen. Compar. Endocrinol. 44, 302-306. doi: 10. 1016/0016-6480(81)90005-8

Bounhiol, J.-J. (1938). Recherches expérimentales sur le déterminisme de la métamorphose chez les Lépidopterès. Bull. Biol. Fr. Belg. Suppl. 24, $1-199$.

Bounhiol, J. J. (1939). Recentes recherches experimentales sur les insects. Les fonctions des corps allates (corpora allata). Arch. Zool. Exper. Gen. 81, 54-63.

Bounhiol, J.-J. (1945). Destin independent lors de la nymphose des trois parties formées dans un ver a soie par deux ligatures plus ou moins espacées. $C$. $R$. Acad. Ser. Soc. Biol. Bordeaux 139, 842-844.

Bowers, W. S., Fales, H. M., Thompson, M. J., and Uebel, E. C. (1966). Juvenile hormone: identification of an active compound from balsam fir. Science 154, 1020-1021. doi: 10.1126/science.154.3752.1020

Bownes, M., and Rembold, H. (1987). The titre of juvenile hormone during the pupal and adult stages of the life cycle of Drosophila melanogaster. Eur. J. Biochem. 164, 709-712. doi: 10.1111/j.1432-1033.1987.tb1 1184.x

Brown-Séquard, D. R. (1889). Note on the effects produced on man by subcutaneous injections of a liquid obtained from the testicles of animals. Lancet 134, 105-107. doi: 10.1016/s0140-6736(00)64118-1

Bryant, P. J., and Sang, J. H. (1968). Drosophila: lethal derangements of metamorphosis and modifications of gene expression caused by juvenile hormone mimics. Nature 220, 393-394. doi: 10.1038/220393a0

Caveney, S., and Podgorski, C. (1975). Intercellular communication in a positional field. Ultrastructural correlates and tracer analysis of communication between 
insect epidermal cells. Tissue Cell 7, 559-574. doi: 10.1016/0040-8166(75) 90026-9

Charles, J. P., Iwema, T., Epa, V. C., Takaki, K., Rynes, J., and Jindra, M. (2011). Ligand-binding properties of a juvenile hormone receptor, Methoprenetolerant. Proc. Natl. Acad. Sci. U.S.A. 108, 21128-21133. doi: 10.1073/pnas. 1116123109

Charles, J.-P., Wojtasek, H., Lentz, A. J., Thomas, B. A., Bonning, B. C., Palli, S. R., et al. (1996). Purification and reassessment of ligand binding by the recombinant, putative juvenile hormone receptor of the tobacco hornworm, Manduca sexta. Arch. Insect Biochem. Physiol. 31, 371-393. doi: 10.1002/(sici) 1520-6327(1996)31:4<371::aid-arch2>3.0.co;2-z

Cymborowski, B. (1981). "Stefan Kopeć," in Proceedings of the Part 1 International Conference Regulation of Insect Development and Behaviour, eds F. Sehnal, A. Zabza, J. J. Menn, and B. Cymborowski (Wrocław: Wrocław Technical University Press), I-II.

Daimon, T., Kozaki, T., Niwa, R., Kobayashi, I., Furuta, K., Namiki, T., et al. (2012). Precocious metamorphosis in the juvenile hormone-deficient mutant of the silkworm, Bombyx mori. PLoS Genet. 8:e1002486. doi: 10.1371/journal.pgen. 1002486

Daimon, T., Uchibori, M., Nakao, H., Sezutsu, H., and Shinoda, T. (2015). Knockout silkworms reveal a dispensable role for juvenile hormones in holometabolous life cycle. Proc. Natl. Acad. Sci. U.S.A. 112, E4226-E4235. doi: $10.1073 /$ pnas. 1506645112

Davey, K. G. (1996). Hormonal control of the follicular epithelium during vitellogenin uptake. Invert. Reprod. Dev. 30, 249-254. doi: 10.1080/07924259. 1996.9672551

Davey, K. G. (2000). The modes of action of juvenile hormones: some questions we ought to ask. Insect Biochem. Mol. Biol. 30, 663-669. doi: 10.1016/s09651748(00)00037-0

Davey, K. G., and Huebner, E. (1974). The response of the follicle cells of Rhodnius prolixus to juvenile hormone and antigonadotropin in vitro. Can. J. Zool. 52, 1407-1412. doi: 10.1139/z74-178

Dominick, O. S., and Truman, J. W. (1985). The physiology of wandering behavior in Manduca sexta. II. The endocrine control of wandering behavior. J. Exp. Biol. 117, 45-68.

Fain, M. J., and Riddiford, L. M. (1975). Juvenile hormone titers in the hemolymph during late larval development of the tobacco hornworm, Manduca sexta (L.). Biol. Bull. 149, 506-521. doi: 10.2307/1540383

Fain, M. J., and Riddiford, L. M. (1976). Reassessment of the critical periods for prothoracicotropic hormone and juvenile hormone secretion in the tobacco hornworm, Manduca sexta. Gen. Comp. Endocrinol. 30, 131-141. doi: 10.1016/ 0016-6480(76)90092-7

Fristrom, D., and Fristrom, J. W. (1993). "The metamorphic development of the adult epidermis," in The Development of Drosophila melanogaster, Vol. II, eds M. Bate and A. Martinez-Arias (Plainview, NY: Cold Spring Harbor Laboratory Press), 843-897.

Fukuda, S. (1940a). Induction of pupation in silkworm by transplanting the prothoracic gland. Proc. Imp. Acad. Japan 16, 414-416. doi: 10.2183/pjab1912. 16.414

Fukuda, S. (1940b). Hormonal control of molting and pupation in the silkworm. Proc. Imp. Acad. Japan 16, 417-420. doi: 10.2183/pjab1912.16.417

Fukuda, S. (1944). The hormonal mechanism of larval molting and metamorphosis in the silkworm. J. Fac. Sci. Tokyo Univ. Sec. IV 6, 477-532.

Gibbs, D., and Riddiford, L. M. (1977). Prothoracicotropic hormone in Manduca sexta: localization by a larval assay. J. Exp. Biol. 66, 255-266.

Gilbert, L. I., Rybczynski, R., Song, Q., Mizoguchi, A., Morreale, R., Smith, W. A., et al. (2000). Dynamic regulation of prothoracic gland ecdysteroidogenesis: Manduca sexta recombinant prothoracicotropic hormone and brain extracts have identical effects. Insect Biochem. Mol. Biol. 30, 1079-1089. doi: 10.1016/ s0965-1748(00)00083-7

Gilbert, L. I., Rybczynski, R., and Warren, J. T. (2002). Control and biochemical nature of the ecdysteroidogenic pathway. Annu. Rev. Entomol. 47, 883-916. doi: 10.1146/annurev.ento.47.091201.145302

Godlewski, J., Wang, S., and Wilson, T. G. (2006). Interaction of bHLH-PAS proteins involved in juvenile hormone reception in Drosophila. Biochem. Biophys. Res. Commun. 342, 1305-1311. doi: 10.1016/j.bbrc.2006.02.097

Goodman, W. G., and Cusson, M. (2012). "The juvenile hormones," in Insect Endocrinology, ed. L. I. Gilbert (Amsterdam: Elsevier), 310-365.
Goodman, W. G., and Granger, N. A. (2005). "The juvenile hormones," in Comprehensive Molecular Insect Science, eds L. I. Gilbert, K. Iatrou, and S. S. Gill (Amsterdam: Elsevier), 319-408.

Gudernatsch, J. F. (1912). Feeding experiments on tadpoles. I. The influence of specific organs given as food on growth and differentiation. A contribution to the knowledge of organs with internal secretion. Wilhelm Roux Arch. Entwickl. Mech. Org. 35, 457-483. doi: 10.1007/bf02277051

Hall, B. L., and Thummel, C. S. (1998). The RXR homolog ultraspiracle is an essential component of the Drosophila ecdysone receptor. Development 125, 4709-4717.

Handler, A. M. (1982). Ecdysteroid titers during pupal and adult development in Drosophila melanogaster. Dev. Biol. 93, 73-82. doi: 10.1016/0012-1606(82) 90240-8

Hintze-Podufal, C. (1996). In Memoriam. Hans Piepho, 1909-1993. Entomol. Gener. 20, 221-223.

Hiruma, K., and Kaneko, Y. (2013). Hormonal regulation of insect metamorphosis with special reference to juvenile hormone biosynthesis. Curr. Top. Dev. Biol. 103, 73-100. doi: 10.1016/b978-0-12-385979-2.00003-4

Hiruma, K., and Riddiford, L. M. (2010). Developmental expression of mRNAs for epidermal and fat body proteins and hormonally regulated transcription factors in the tobacco hornworm. Manduca sexta. J. Insect Physiol. 56, 1390-1395. doi: 10.1016/j.jinsphys.2010.03.029

Inui, T., and Daimon, T. (2017). Implantation assays using the integument of early stage Bombyx larvae: insights into the mechanisms underlying the acquisition of competence for metamorphosis. J. Insect Physiol. 100, 35-42. doi: 10.1016/j. jinsphys.2017.05.002

Jindra, M. (2019). Where did the pupa come from? The timing of juvenile hormone signalling supports homology between stages of hemimetabolous and holometabolous insects. Philos. Trans. R. Soc. Lond. B Biol. Sci. 374, 20190064. doi: 10.1098/rstb.2019.0064

Jindra, M., Bellés, X., and Shinoda, T. (2015a). Molecular basis of juvenile hormone signaling. Curr. Opin. Insect Sci. 11, 39-46. doi: 10.1016/j.cois.2015. 08.004

Jindra, M., Uhlirova, M., Charles, J.-P., Smykal, V., and Hill, R. J. (2015b). Genetic evidence for function of the bHLH-PAS protein Gce/Met as a juvenile hormone receptor. PLoS Genet. 11:e1005394. doi: 10.1371/journal.pgen.100 5394

Jing, Y. P., An, H., Zhang, S., Wang, N., and Zhou, S. (2018). Protein kinase C mediates juvenile hormone-dependent phosphorylation of $\mathrm{Na}^{+} / \mathrm{K}^{+}$-ATPase to induce ovarian follicular patency for yolk protein uptake. J. Biol. Chem. 293, 20112-20122. doi: 10.1074/jbc.ra118.005692

Jones, D., Jones, G., and Teal, P. E. (2013). Sesquiterpene action, and morphogenetic signaling through the ortholog of retinoid $\mathrm{X}$ receptor, in higher Diptera. Gen. Comp. Endocrinol. 194, 326-335.

Jones, G., Jones, D., Teal, P., Sapa, A., and Wozniak, M. (2006). The retinoid$\mathrm{X}$ receptor ortholog, ultraspiracle, binds with nanomolar affinity to an endogenous morphogenetic ligand. FEBS J. 273, 4983-4996. doi: 10.1111/j. 1742-4658.2006.05498.x

Jones, G., and Sharp, P. A. (1997). Ultraspiracle: an invertebrate nuclear receptor for juvenile hormones. Proc. Natl. Acad. Sci. U.S.A. 94, 13499-13503. doi: 10.1073/pnas.94.25.13499

Judy, K. J., Schooley, D. A., Dunham, L. L., Hall, M. S., Bergot, J., and Siddall, J. B. (1973). Isolation, structure, and absolute configuration of a new natural juvenile hormone from Manduca sexta. Proc. Natl. Acad. Sci. U.S.A. 70, 1509-1513. doi: 10.1073/pnas.70.5.1509

Kataoka, H., Toschi, A., Li, J. P., Carney, R. L., Schooley, D. A., and Kramer, S. J. (1989). Identification of an allatotropin from adult Manduca sexta. Science 243, 1481-1483. doi: 10.1126/science.243.4897.1481

Knight, K. (2014). Rhodnius respiration depends on multiple factors. J. Exp. Biol. 217:2622. doi: 10.1242/jeb.111104

Konopova, B., and Jindra, M. (2007). Juvenile hormone resistance gene Methoprene-tolerant controls entry into metamorphosis in the beetle Tribolium castaneum. Proc. Natl. Acad. Sci. U.S.A. 104, 10488-10493. doi: 10.1073/pnas. 0703719104

Konopova, B., Smykal, V., and Jindra, M. (2011). Common and distinct roles of juvenile hormone signaling genes in metamorphosis of holometabolous and hemimetabolous insects. PLoS One 6:e28728. doi: 10.1371/journal.pone. 0028728 
Kopeć, S. (1917). Experiments on metamorphosis of insects. Bull. Int. Acad. Sci. Cracovie (B) 57-60.

Kopeć, S. (1922). Studies on the necessity of the brain for the inception of insect metamorphosis. Biol. Bull. 42, 323-342. doi: 10.2307/1536759

Kotaki, T., Shinada, T., Kaihara, K., Ohfune, Y., and Numata, H. (2009). Structure determination of a new juvenile hormone from a heteropteran insect. Org. Lett. 11, 5234-5237. doi: 10.1021/ol902161x

Koyama, T., Syropyatova, M. O., and Riddiford, L. M. (2008). Insulin/IGF signaling regulates the change in commitment in imaginal discs and primordia by overriding the effect of juvenile hormone. Dev. Biol. 324, 258-265. doi: 10.1016/ j.ydbio.2008.09.017

Krogh, A. (1929). The progress of physiology. Science 70, 200-204.

Kühn, A., and Piepho, H. (1940). Über die ausbildung der schuppen in hauttransplantaten von schmetterlingen. Biol. Zbl. 60, 1-22.

Lamy, M., and Delsol, M. (1980). Jean-Jacques bounhiol, 1905-1979. Ann. Endocrinol. 41, 153-156.

Lawrence, P. A. (1969). Cellular differentiation and pattern formation during metamorphosis of the milkweed bug Oncopeltus. Dev. Biol. 19, 12-40. doi: 10.1016/0012-1606(69)90068-2

LeBlanc, G. A., and Medlock, E. K. (2015). Males on demand: the environmentalneuro-endocrine control of male sex determination in daphnids. FEBS J. 282, 4080-4093. doi: 10.1111/febs.13393

Lee, H. T.-Y. (1948). A comparative morphological study of the prothoracic glandular bands of some lepidopterous larvae with special reference to their innervation. Ann. Ent. Soc. Amer. 41, 200-205. doi: 10.1093/aesa/41. 2.200

Li, M., Mead, E. A., and Zhu, J. (2011). Heterodimer of two bHLH-PAS proteins mediates juvenile hormone-induced gene expression. Proc. Natl. Acad. Sci. U.S.A. 108, 638-643. doi: 10.1073/pnas.1013914108

$\mathrm{Liu}, \mathrm{P} ., \mathrm{Fu}, \mathrm{X}$., and $\mathrm{Zhu}$, J. (2018). Juvenile hormone-regulated alternative splicing of the taiman gene primes the ecdysteroid response in adult mosquitoes. Proc. Natl. Acad. Sci. U.S.A. 115, E7738-E7747. doi: 10.1073/pnas.180814 6115

Liu, P., Peng, H. J., and Zhu, J. (2015). Juvenile hormone-activated phospholipase C pathway enhances transcriptional activation by the Methoprene-tolerant protein. Proc. Natl. Acad. Sci. U.S.A. 112, E1871-E1879. doi: 10.1073/pnas. 1423204112

Liu, Y., Sheng, Z., Liu, H., Wen, D., He, Q., Wang, S., et al. (2009). Juvenile hormone counteracts the bHLH-PAS transcription factors MET and GCE to prevent caspase-dependent programmed cell death in Drosophila. Development 136, 2015-2025. doi: 10.1242/dev.033712

Lozano, J., and Belles, X. (2011). Conserved repressive function of Krüppel homolog 1 on insect metamorphosis in hemimetabolous and holometabolous species. Sci. Rep. 1:163. doi: 10.1038/srep00163

Lozano, J., Kayukawa, T., Shinoda, T., and Belles, X. (2014). A role for Taiman in insect metamorphosis. PLoS Genet. 10:e1004769. doi: 10.1371/journal.pgen. 1004769

Lyonet, P. (1762). Traite Anatomique de la Chenille, qui Ronge le Bois de Saule. Cambridge: viaLibri Limited.

MacWhinnie, S. G. B., Allee, J. P., Nelson, C. A., Riddiford, L. M., Truman, J. W., and Champlin, D. T. (2005). The role of nutrition in creation of the eye imaginal disc and initiation of metamorphosis in Manduca sexta. Dev. Biol. 285, 285-297. doi: 10.1016/j.ydbio.2005.06.021

Marchal, E., Hult, E. F., Huang, J., Stay, B., and Tobe, S. S. (2013). Diploptera punctata as a model for studying the endocrinology of arthropod reproduction and development. Gen. Comp. Endocrinol. 188, 85-93. doi: 10.1016/j.ygcen. 2013.04.018

Meyer, A. S., Schneiderman, H. A., Hanzmann, E., and Ko, J. H. (1968). The two juvenile hormones from the cecropia silk moth. Proc. Natl. Acad. Sci. U.S.A. 60, 853-860. doi: 10.1073/pnas.60.3.853

Minakuchi, C., Namiki, T., and Shinoda, T. (2009). Krüppel homolog 1, an early juvenile hormone-response gene downstream of Methoprene-tolerant, mediates its anti-metamorphic action in the red flour beetle Tribolium castaneum. Dev. Biol. 325, 341-350. doi: 10.1016/j.ydbio.2008.10.016

Minakuchi, C., Zhou, X., and Riddiford, L. M. (2008). Krüppel homolog 1 (Kr-h1) mediates juvenile hormone action during metamorphosis of Drosophila melanogaster. Mech. Dev. 125, 91-105. doi: 10.1016/j.mod.2007. 10.002
Mitsui, T., and Riddiford, L. M. (1976). Pupal cuticle formation by Manduca sexta epidermis in vitro: patterns of ecdysone sensitivity. Dev. Biol. 54, 172-186. doi: 10.1016/0012-1606(76)90297-9

Mitsui, T., and Riddiford, L. M. (1978). Hormonal requirements for the larvalpupal transformation of the epidermis of Manduca sexta in vitro. Dev. Biol. 62, 193-205. doi: 10.1016/0012-1606(78)90101-x

Mitsui, T., Riddiford, L. M., and Bellamy, G. (1979). Metabolism of juvenile hormone by the epidermis of the tobacco hornworm, Manduca sexta. Insect Biochem. 9, 637-643. doi: 10.1016/0020-1790(79)90103-3

Miura, T. (2019). Juvenile hormone as a physiological regulator mediating phenotypic plasticity in pancrustaceans. Dev. Growth Diff. 61, 85-96. doi: $10.1111 /$ dgd.12572

Miyakawa, H., Sato, T., Song, Y., Tollefsen, K. E., and Iguchi, T. (2018). Ecdysteroid and juvenile hormone biosynthesis, receptors and their signaling in the freshwater microcrustacean Daphnia. J. Steroid Biochem. Mol. Biol. 184, 62-68. doi: 10.1016/j.jsbmb.2017.12.006

Miyakawa, H., Toyota, K., Hirakawa, I., Ogino, Y., Miyagawa, S., Oda, S., et al. (2013). A mutation in the receptor Methoprene-tolerant alters juvenile hormone response in insects and crustaceans. Nat. Comm. 4:1856. doi: 10.1038/ ncomms 2868

Nabert, A. (1912). Die Corpora allata der Insekten. Zeitschr. Wiss. Zool. 104, 181-358.

Nagaraju, G. P. (2011). Reproductive regulators in decapod crustaceans: an overview. J. Exp. Biol. 214, 3-16. doi: 10.1242/jeb.047183

Nijhout, H. F. (1975a). A threshold size for metamorphosis in the tobacco hornworm, Manduca sexta (L.). Biol. Bull. 149, 214-225. doi: 10.2307/1540491

Nijhout, H. F. (1975b). Dynamics of juvenile hormone action in larvae of the tobacco hornworm, Manduca sexta (L.). Biol. Bull. 149, 568-579. doi: 10.2307/ 1540387

Nijhout, H. F. (1995). Insect Hormones. Princeton, NJ: Princeton University Press. Nijhout, H. F., Riddiford, L. M., Mirth, C., Shingleton, A. W., Suzuki, Y., and Callier, V. (2014). The developmental control of size in insects. Wiley Interdiscip. Rev. Dev. Biol. 3, 113-134. doi: 10.1002/wdev.124

Nijhout, H. F., and Williams, C. M. (1974a). Control of moulting and metamorphosis in the tobacco hornworm, Manduca sexta (L.): growth of the last-instar larva and the decision to pupate. J. Exp. Biol. 61, 481-491.

Nijhout, H. F., and Williams, C. M. (1974b). Control of moulting and metamorphosis in the tobacco hornworm, Manduca sexta (L.): cessation of juvenile hormone secretion as a trigger for pupation. J. Exp. Biol. 61, 493-501.

Ninov, N., Chiarelli, D. A., and Martín-Blanco, E. (2007). Extrinsic and intrinsic mechanisms directing epithelial cell sheet replacement during Drosophila metamorphosis. Development 134, 367-379. doi: 10.1242/dev. 02728

Ninov, N., Manjón, C., and Martín-Blanco, E. (2009). Dynamic control of cell cycle and growth coupling by ecdysone, EGFR, and PI3K signaling in Drosophila histoblasts. PLoS Biol. 7:e1000079. doi: 10.1371/journal.pbio.1000079

Noriega, F. G. (2014). Juvenile hormone biosynthesis in insects: what is new, what do we know, and what questions remain? Int. Sch. Res. Notices 2014:967361. doi: $10.1155 / 2014 / 967361$

Ojani, R., Liu, P., Fu, X., and Zhu, J. (2016). Protein kinase C modulates transcriptional activation by the juvenile hormone receptor Methoprenetolerant. Insect Biochem. Mol. Biol. 70, 44-52. doi: 10.1016/j.ibmb.2015.12. 001

Olmstead, A. W., and Leblanc, G. A. (2002). Juvenoid hormone methyl farnesoate is a sex determinant in the crustacean Daphnia magna. J. Exp. Zool. 293, 736-739. doi: 10.1002/jez.10162

Oro, A. E., McKeown, M., and Evans, R. M. (1992). The Drosophila retinoid X receptor homolog ultraspiracle functions in both female reproduction and eye morphogenesis. Development 115, 449-462.

Palli, S. R., Touhara, K., Charles, J.-P., Bonning, B. C., Atkinson, J. K., Trowell, S. C., et al. (1994). A nuclear juvenile hormone-binding protein from larvae of Manduca sexta: a putative receptor for the metamorphic action of juvenile hormone. Proc. Natl. Acad. Sci. U.S.A. 91, 6191-6195. doi: 10.1073/pnas.91.13. 6191

Parthasarathy, R., Farkas, R., and Palli, S. R. (2012). Recent progress in juvenile hormone analogs (JHA) research. Adv. Insect Physiol. 43, 353-436. doi: 10. 1016/b978-0-12-391500-9.00005-x 
Pecasse, F., Beck, Y., Ruiz, C., and Richards, G. (2000). Krü̈ppel-homolog, a stage-specific modulator of the prepupal ecdysone response, is essential for Drosophila metamorphosis. Dev. Biol. 221, 53-67. doi: 10.1006/dbio.2000.9687

Perez, C. (1910). Recherches histologiques sur la metamorphose des Muscides Calliphora erythrocephalea Mg. Arch. Zool. Exp. Gen. 4, 1-274, 1-XVI.

Peter, M. G., Shirk, P. D., Dahm, K. H., and Röller, H. (1981). On the specificity of juvenile hormone biosynthesis in the male Cecropia moth. Z. Naturforsch. 36c, 579-585. doi: 10.1515/znc-1981-7-812

Pfeiffer, I. W. (1939). Experimental study of the function of the corpora allata in the grasshopper, Melanoplus differentialis. J. Exp. Zool. 82, 439-461. doi: 10.1002/jez.1400820307

Pflugfelder, O. (1937). Bau, entwicklung und funktion der Corpora allata und cardiaca von Dixippus morosus. Br. Z. Wiss. Zool. 149, 477-512.

Phillips, K. (2004). Happy anniversary JEB! J. Exp. Biol. 207, 1-3. doi: 10.1242/jeb. 00776

Piepho, H. (1938a). Wachstum und totale metamorphose an hautimplantaten bei der wachsmotte Galleria mellonella. L. Biol Zbl. 58, 356-366.

Piepho, H. (1938b). Über die experimentelle ausl?sbarkeit überzähliger häutungen und vorzeitiger verpuppung an hautstücken bei kleinschmetterlingen. Naturwissenschaften 52, 141-142. doi: 10.1007/bf00631948

Piepho, H. (1942). Untersuchungen zur entwicklungsphysiologie der insektenmetamorphose : über die puppenhäutung der wachsmotte Galleria mellonella L. Wilhelm Roux Arch. EntwMech. Org. 141, 500-583. doi: 10.1007/bf00596490

Postlethwait, J. H. (1974). Juvenile hormone and the adult development of Drosophila. Biol. Bull. 147, 119-135. doi: 10.2307/1540573

Prestwich, G. D., Touhara, K., Riddiford, L. M., and Hammock, B. D. (1994). Larva lights: a decade of photoaffinity labeling with juvenile hormone analogues. Insect Biochem. Mol. Biol. 24, 747-761. doi: 10.1016/0965-1748(94)90104-X

Qu, Z., Bendena, W. G., Tobe, S. S., and Hui, J. (2018). Juvenile hormone and sesquiterpenoids in arthropods: biosynthesis, signaling, and role of MicroRNA. J. Steroid Biochem. Mol. Biol. 184, 69-76. doi: 10.1016/j.jsbmb.2018. 01.013

Radtke, A. (1942). Hemmung der verpuppung beim mehlkäfer Tenebroadio molitor L. Naturwissenschafen 29, 451-453, 469.

Raikhel, A. S., Brown, M. R., and Belles, X. (2005). "Hormonal control of reproductive processes," in Comprehensive Molecular Insect Science, Vol. 3, eds L. I. Gilbert, K. Iatrou, and S. S. Gill (Amsterdam: Elsevier), 433-491. doi: 10.1016/b0-44-451924-6/00040-5

Restifo, L. L., and Wilson, T. G. (1998). A juvenile hormone agonist reveals distinct developmental pathways mediated by ecdysone-inducible Broadcomplex transcription factors. Dev. Genet. 22, 141-159. doi: 10.1002/(sici) 1520-6408(1998)22:2<141::aid-dvg4>3.0.co;2-6

Richard, D. S., Applebaum, S. W., and Gilbert, L. I. (1989). Developmental regulation of juvenile hormone biosynthesis by the ring gland of Drosophila melanogaster. J. Comp. Physiol. B. Biochem. System. Environ. Physiol. 159, 383-387. doi: 10.1007/bf00692410

Riddiford, L. M. (1976). Hormonal control of insect epidermal cell commitment in vitro. Nature 259, 115-117. doi: 10.1038/259115a0

Riddiford, L. M. (1978). Ecdysone-induced change in cellular commitment of the epidermis of the tobacco hornworm, Manduca sexta, at the initiation of metamorphosis. Gen. Comp. Endocrinol. 34, 438-446. doi: 10.1016/00166480(78)90284-8

Riddiford, L. M. (2008). Juvenile hormone action: a 2007 perspective. J. Insect Physiol. 54, 895-901. doi: 10.1016/j.jinsphys.2008.01.014

Riddiford, L. M., and Ashburner, M. (1991). Effects of juvenile hormone mimics on larval development and metamorphosis of Drosophila melanogaster. Gen. Comp. Endocrinol. 82, 172-183. doi: 10.1016/0016-6480(91)90181-5

Riddiford, L. M., Cherbas, P., and Truman, J. W. (2001). Ecdysone receptors and their biological actions. Vitam. Horm. 60, 1-73. doi: 10.1016/s0083-6729(00) 60016- $\mathrm{x}$

Riddiford, L. M., Curtis, A. T., and Kiguchi, K. (1979). Culture of the epidermis of the tobacco hornworm, Manduca sexta. Tissue Cult. Assn. Man. 5, 975-985.

Riddiford, L. M., Kiguchi, K., Roseland, C. R., Chen, A. C., and Wolfgang, W. J. (1980). "Cuticle formation and sclerotization in vitro by the epidermis of the tobacco hornworm, Manduca sexta," in Invertebrate Systems In Vitro, eds E. Kurstak, K. Maramorosch, and A. Dubendorfer (Amsterdam: Elsevier), $103-115$.
Riddiford, L. M., Truman, J. W., Mirth, C. K., and Shen, Y. (2010). A role for juvenile hormone in the prepupal development of Drosophila melanogaster. Development 137, 1117-1126. doi: 10.1242/dev.037218

Riddiford, L. M., Truman, J. W., and Nern, A. (2018). Juvenile hormone reveals mosaic developmental programs in the metamorphosing optic lobe of Drosophila melanogaster. Biol. Open 7:bio034025. doi: 10.1242/bio.03 4025

Rust, M. K., and Hemsarth, W. (2019). Synergism of adulticides and insect growth regulators against larval cat fleas (Siphonaptera: Pulicidae). J. Med. Entomol. 56, 790-795. doi: 10.1093/jme/tjy239

Rust, M. K., Lance, W., and Hemsarth, H. (2016). Synergism of the IGRs methoprene and pyriproxyfen against larval cat fleas (Siphonaptera: Pulicidae). J. Med. Entomol. 53, 629-633. doi: 10.1093/jme/tjw010

Röller, H., and Dahm, K. H. (1968). The chemistry and biology of juvenile hormone. Rec. Prog. Horm. Res. 24, 651-680. doi: 10.1016/b978-1-4831-98279.50018-6

Röller, H., and Dahm, K. H. (1970). The identity of juvenile hormone produced by corpora allata in vitro. Naturwissenschaften 9, 454-455. doi: 10.1007/ bf00607739

Röller, H., Dahm, K. H., Sweeley, C. C., and Trost, B. M. (1967). The structure of juvenile hormone. Angew. Chem. 6, 179-180.

Safranek, L., and Riddiford, L. M. (1975). The biology of the black larval mutant of the tobacco hornworm. Manduca sexta. J. Insect Physiol. 21, 1931-1938. doi: 10.1016/0022-1910(75)90225-5

Santos, C. G., Humann, F. C., and Hartfelder, K. (2019). Juvenile hormone signaling in insect oogenesis. Curr. Opin. Insect Sci. 31, 43-48. doi: 10.1016/j.cois.2018. 07.010

Sasorith, S., Billas, I. M., Iwema, T., Moras, D., and Wurtz, J. M. (2002). Structurebased analysis of the ultraspiracle protein and docking studies of putative ligands. J. Insect Sci. 2:25. doi: 10.1093/jis/2.1.25

Scharrer, B. (1946). The role of the corpora allata in the development of Leucophaea (Orthoptera). Endocrinology 38, 35-45. doi: 10.1210/endo-38-1-35

Schooley, D. A., Baker, F. C., Tsai, L. W., Miller, C. A., and Jamieson, G. C. (1984). "Juvenile hormones 0, I, and II exist only in Lepidoptera," in Biosynthesis, Metabolism and Mode of Action of Insect Hormones, eds J. A. Hoffmann and M. Porchet (Berlin: Springer Verlag), 373-383. doi: 10.1007/978-3-642-69922$1 \_36$

Schubiger, M., Carré, C., Antoniewski, C., and Truman, J. W. (2005). Liganddependent de-repression via EcR/USP acts as a gate to coordinate the differentiation of sensory neurons in the Drosophila wing. Development 132, 5239-5248. doi: 10.1242/dev.02093

Shepherd, J. G. (1974). Activation of saturniid moth sperm by a secretion of the male reproductive tract. J. Insect Physiol. 20, 2107-2122. doi: 10.1016/00221910(74)90037-7

Shinoda, T., Hiruma, K., Charles, J.-P., and Riddiford, L. M. (1997). Hormonal regulation of JP29 during larval development and metamorphosis in the tobacco hornworm, Manduca sexta. Arch. Insect Biochem. Physiol. 34, 409-428. doi: 10.1002/(sici)1520-6327(1997)34:4<409::aid-arch2>3.0.co;2-n

Shionoya, M., Matsubayashi, H., Asahina, M., Kuniyoshi, H., Nagata, S., Riddiford, L. M., et al. (2003). Molecular cloning of the prothoracicotropic hormone from the tobacco hornworm, Manduca sexta. Insect Biochem. Mol. Biol. 33, 795-801. doi: 10.1016/s0965-1748(03)00078-x

Shirk, P. D., Dahm, K. H., and Röller, H. (1976). The accessory sex glands as the repository for juvenile hormone in male cecropia moths. Zeitschr. Naturforsch. Sec. C Biosci. 31, 199-200. doi: 10.1515/znc-1976-3-421

Sláma, K., and Williams, C. M. (1965). Juvenile hormone activity for the bug Pyrrhocoris apterus. Proc. Natl. Acad. Sci. U.S.A. 54, 411-414. doi: 10.1073/pnas. 54.2.411

Sláma, K., and Williams, C. M. (1966). The juvenile hormone. V. The sensitivity of the bug, Pyrrhocoris apterus, to a hormonally active factor in American paper-pulp. Biol. Bull. 130, 235-246.

Sliter, T. J., Sedlak, B. J., Baker, F. C., and Schooley, D. A. (1987). Juvenile hormone in Drosophila melanogaster. Idenitfication and titer determination during development. Insect Biochem. 17, 161-165. doi: 10.1016/0020-1790(87) 90156-9

Smith, W., and Rybczynski, R. (2012). "Prothoracicotropic hormone," in Insect Endocrinology, ed. L. I. Gilbert (Amsterdam: Elsevier), 1-62. doi: 10.1016/b9780-12-384749-2.10001-9 
Smykal, V., Daimon, T., Kayukawa, T., Takaki, K., Shinoda, T., and Jindra, M. (2014). Importance of juvenile hormone signaling arises with competence of insect larvae to metamorphose. Dev. Biol. 390, 221-230. doi: 10.1016/j.ydbio. 2014.03.006

Soma, K. K. (2006). Testosterone and aggression: berthold, birds and beyond. J. Neuroendocrin. 18, 543-551. doi: 10.1111/j.1365-2826.2006.01440.x

Staal, G. B. (1975). Insect growth regulators with juvenile hormone activity. Ann. Rev. Entomol. 20, 417-460. doi: 10.1146/annurev.en.20.010175.002221

Starling, E. H. (1905). Croonian lecture: on the chemical correlation of the function of the body. Lancet 2, 339-341. doi: 10.1016/s0140-6736(01)11877-5

Stay, B., and Tobe, S. S. (2007). The role of allatostatins in juvenile hormone synthesis in insects and crustaceans. Ann. Rev. Entomol. 52, 277-299. doi: 10.1146/annurev.ento.51.110104.151050

Suzuki, Y., Koyama, T., Hiruma, K., Riddiford, L. M., and Truman, J. W. (2013). A molt timer is involved in the metamorphic molt in Manduca sexta larvae. Proc. Natl. Acad. Sci. U.S.A. 110, 12518-12525. doi: 10.1073/pnas.131140 5110

Svácha, P. (1992). What are and what are not imaginal discs: reevaluation of some basic concepts (Insecta. Holometabola). Dev. Biol. 154, 101-117. doi: 10.1016/0012-1606(92)90052-i

Thomsen, E. (1940). Relation between corpus allatum and ovaries in adult flies (Muscidre). Nature 145, 28-29. doi: 10.1038/145028a0

Thummel, C. S. (1990). Puffs and gene regulation-molecular insights into the Drosophila ecdysone regulatory hierarchy. BioEssays 12, 561-568. doi: 10.1002/ bies.950121202

Toyota, K., Miyakawa, H., Hiruta, C., Furuta, K., Ogino, Y., Shinoda, T., et al. (2015). Methyl farnesoate synthesis is necessary for the environmental sex determination in the water flea Daphnia pulex. J. Insect Physiol. 80, 22-30. doi: 10.1016/j.jinsphys.2015.02.002

Truman, J. W. (1972). Physiology of insect rhythms I. Circadian organization of the endocrine events underlying the moulting cycle of larval tobacco hornworms. J. Exp. Biol. 57, 805-820.

Truman, J. W. (2019). The evolution of insect metamorphosis. Curr. Biol. 29, R1252-R1268.

Truman, J. W., Hiruma, K., Allee, J. P., MacWhinnie, S. G. B., Champlin, D. T., and Riddiford, L. M. (2006). Juvenile hormone is required to couple imaginal disc formation with nutrition in insects. Science 312, 1385-1388. doi: 10.1126/ science. 1123652

Truman, J. W., and Riddiford, L. M. (1974). Physiology of insect rhythms. III. The temporal organization of the endocrine events underlying pupation of the tobacco hornworm. J. Exp. Biol. 60, 371-382.

Truman, J. W., and Riddiford, L. M. (2019). The evolution of insect metamorphosis: a developmental and endocrine view. Philos. Trans. R. Soc. B 374:20190070. doi: 10.1098/rstb.2019.0070

Truman, J. W., Riddiford, L. M., and Safranek, L. (1973). Hormonal control of cuticle coloration in the tobacco hornworm: basis of an ultrasensitive bioassay for juvenile hormone. J. Insect Physiol. 19, 195-203. doi: 10.1016/00221910(73)90232-1

Truman, J. W., Riddiford, L. M., and Safranek, L. (1974). Temporal patterns of response to ecdysone and juvenile hormone in the epidermis of the tobacco hornworm, Manduca sexta. Dev. Biol. 39, 247-262. doi: 10.1016/0012-1606(74) 90238-3

Ureña, E., Chafino, S., Manjón, C., Franch-Marro, X., and Martin, D. (2016). The occurrence of the holometabolous pupal stage requires the interaction between E93, Krüppel-homolog 1 and Broad-Complex. PLoS Genet. 12:e1006020. doi: 10.1371/journal.pgen.1006020

Ureña, E., Manjón, C., Franch-Marro, X., and Martin, D. (2014). Transcription factor E93 specifies adult metamorphosis in hemimetabolous and holometabolous insects. Proc. Natl. Acad. Sci. U.S.A. 111, 7024-7029. doi: 10.1073/pnas.1401478111

Uyehara, C. M., Nystrom, S. L., Niederhuber, M. J., Leatham-Jensen, M., Ma, Y., Buttitta, L. A., et al. (2017). Hormone-dependent control of developmental timing through regulation of chromatin accessibility. Genes Dev. 31, 862-875. doi: $10.1101 / \operatorname{gad} .298182 .117$

Villalobos-Sambucaro, M. J., Nouzova, M., Ramirez, C. E., Eugenia Alzugaray, M., Fernandez-Lima, F., Ronderos, J. R., and Noriega, F. G. (2020). The juvenile hormone described in Rhodnius prolixus by Wigglesworth is juvenile hormone III skipped bisepoxide. Sci. Rep. 10:3091. doi: 10.1038/s41598-020-59495-1
Vogt, M. (1942). Weiteres zur frage der artspezifität gonadotroper hormone. Untersuchungen an Drosophila-arten. Wilhelm Roux Arch. 141, 424-454. doi: 10.1007/bf00596488

Walton, W. E., and Eldridge, B. E. (2020). UC IPM Pest Notes:Mosquitoes. Oakland, CA: UC ANR Publication, 7451.

Wen, D., Rivera-Perez, C., Abdou, M., Jia, Q., He, Q., Liu, X., et al. (2015). Methyl farnesoate plays a dual role in regulating Drosophila metamorphosis. PLoS Genet. 11:e1005038. doi: 10.1371/journal.pgen.1005038

Wigglesworth, V. B. (1934). The physiology of ecdysis in Rhodnius prolixus (Hemiptera) II. Factors controlling moulting and metamorphosis. Quart. J. Microsc. Sci. 77, 191-222.

Wigglesworth, V. B. (1936). The function of the corpus allatum in the growth and reproduction of Rhodnius prolixus (Hemiptera). Quart. J. Microsc. Sci. 79, 91-121.

Wigglesworth, V. B. (1940). The determination of characters at metamorphosis in Rhodnius prolixus (Hemiptera). J. Exp. Biol. 17, 201-223.

Wigglesworth, V. B. (1952). The thoracic gland in Rhodnius prolixus (Hemiptera) and its role in moulting. J. Exp. Biol. 29, 561-570.

Wigglesworth, V. B. (1953). Determination of cell function in an insect. J. Embryol. Exp. Morph. 1, 269-277.

Wigglesworth, V. B. (1954). The Physiology of Insect Metamorphosis. Cambridge: Cambridge University Press.

Wigglesworth, V. B. (1958). Some methods for assaying extracts of the juvenile hormone in insects. J. Insect Physiol. 2, 73-84. doi: 10.1016/0022-1910(58) 90031-3

Wigglesworth, V. B. (1963). The action of moulting hormone and juvenile hormone at the cellular level in Rhodnius prolixus. J. Exp. Biol. 40, 231-245.

Wigglesworth, V. B. (1973). The role of the epidermal cells in moulding the surface pattern of the cuticle in Rhodnius (Hemiptera). J. Cell Sci. 12, 683-705.

Wigglesworth, V. B. (1985). "Historical perspectives," in Comprehensive Insect Physiology, Biochemistry and Pharmacology, Vol. 7, eds G. A. Kerkut and L. I. Gilbert (Oxford: Pergamon Press), 1-24.

Williams, C. M. (1946). Physiology of insect diapause: the role of the brain in the production and termination of pupal dormancy in the giant silkworm, Platysamia cecropia. Biol. Bull. 90, 234-243. doi: 10.2307/153 8121

Williams, C. M. (1947). Physiology of insect diapause. II. Interaction between the pupal brain and prothoracic glands in the metamorphosis of the giant silkworm, Platysamia cecropia. Biol. Bull. 93, 89-98. doi: 10.2307/1538279

Williams, C. M. (1948). Physiology of insect diapause. III. The prothoracic glands in the Cecropia silkworm, with special reference to their significance in embryonic and postembryonic development. Biol. Bull. 94, 60-65. doi: 10.2307/ 1538210

Williams, C. M. (1952). Physiology of insect diapause. IV. The brain and prothoracic glands as an endocrine system in the Cecropia silkworm. Biol. Bull. 103, 120-138. doi: 10.2307/1538411

Williams, C. M. (1956a). Physiology of insect diapause. X. An endocrine mechanism for the influence of temperature on the diapausing pupa of the Cecropia silkworm. Biol. Bull. 110, 201-218. doi: 10.2307/1538982

Williams, C. M. (1956b). The juvenile hormone of insects. Nature 178, 212-213. doi: $10.1038 / 178212 \mathrm{~b} 0$

Williams, C. M. (1958). The juvenile hormone of insects. Sci. Am. 198, 67-75.

Williams, C. M. (1959). The juvenile hormone. I. Endocrine activity of the corpora allata of the adult Cecropia silkworm. Biol. Bull. 116, 323-338. doi: 10.2307/ 1539218

Williams, C. M. (1961). The juvenile hormone. II. Its role in the endocrine control of molting, pupation, and adult development in the Cecropia silkworm. Biol. Bull. 121, 572-585. doi: 10.2307/1539456

Williams, C. M. (1963). The juvenile hormone. III. Its accumulation and storage in the abdomens of certain male moths. Biol. Bull. 124, 355-367. doi: 10.2307/ 1539485

Williams, C. M., and Kafatos, F. C. (1971). Theoretical aspects of the action of Juvenile Hormone. Bull. Soc. Entom. Suisse 44, 151-162.

Williams, C. M., and Sláma, K. (1966). The juvenile hormone. VI. Effects of the "Paper Factor" on the growth and metamorphosis of the bug, Pyrrhocoris apterus. Biol. Bull. 130, 247-253. doi: 10.2307/1539701

Williams, D. W., and Truman, J. W. (2005). Cellular mechanisms of dendrite pruning in Drosophila: insights from in vivo time-lapse of remodeling dendritic 
arborizing sensory neurons. Development 132, 3631-3642. doi: 10.1242/dev. 01928

Willis, J. H. (1986). The paradigm of stage-specific gene sets in insect metamorphosis: time for revision! Arch. Insect Biochem. Physiol. 3, 47-57. doi: 10.1002/arch.940030707

Willis, J. H., Rezaur, R., and Sehnal, F. (1982). Juvenoids cause some insects to form composite cuticles. J. Embryol. Exp. Morphol. 71, 25-40.

Wilson, T. G., and Fabian, J. (1986). A Drosophila melanogaster mutant resistant to a chemical analog of juvenile hormone. Dev. Biol. 118, 190-201. doi: 10.1016/ 0012-1606(86)90087-4

Wyatt, G. R., and Davey, K. G. (1996). Cellular and molecular actions of juvenile hormone. II. Roles of juvenile hormone in adult insects. Adv. Insect Physiol. 26, 1-155. doi: 10.1016/s0065-2806(08)60030-2

Zhang, Z., Xu, J., Sheng, Z., Sui, Y., and Palli, S. R. (2011). Steroid receptor co-activator is required for juvenile hormone signal transduction through a bHLH-PAS transcription factor, Methoprene tolerant. J. Biol. Chem. 286, 8437-8447. doi: 10.1074/jbc.m110.191684
Zhou, B., and Riddiford, L. M. (2001). Hormonal regulation and patterning of the Broad-Complex in the epidermis and wing discs of the tobacco hornworm, Manduca sexta. Dev. Biol. 231, 125-137. doi: 10.1006/dbio.2000.0143

Zhou, X., and Riddiford, L. M. (2002). Broad specifies pupal development and mediates the 'status quo' action of juvenile hormone on the pupal-adult transformation in Drosophila and Manduca. Development 129, 2259-2269.

Conflict of Interest: The author declares that the research was conducted in the absence of any commercial or financial relationships that could be construed as a potential conflict of interest.

Copyright (c) 2020 Riddiford. This is an open-access article distributed under the terms of the Creative Commons Attribution License (CC BY). The use, distribution or reproduction in other forums is permitted, provided the original author(s) and the copyright owner(s) are credited and that the original publication in this journal is cited, in accordance with accepted academic practice. No use, distribution or reproduction is permitted which does not comply with these terms. 